consecutive cases more than $90 \%$ of the gold injected into living animals.

6. The average time required for carrying out a complete analysis for gold by this method has been less than two hours.

Credit is due to Mr. L. M. Larson for some preliminary work done on this problem.

We take this opportunity of expressing our gratitude to Dr. Lydia M. DeWitt, of the University of Chicago, for her helpful guidance.

Chicago, Iltinóis.

[CONTRIBUtion From The Geophysical, Laboratory of the Carnegie Instithution OF WASHINGTON.]

\title{
THE DETERMINATION OF THE COMPRESSIBILITY OF SOLIDS AT HIGH PRESSURES.
}

By LaAson H. ADAMS, ERskine D. Whimamson and John Johnston.

Received September 7, 1918.

The change of volume of a solid when subjected to hydrostatic pressure is a small quantity and one difficult to measure. It is perhaps for this reason that but few investigators have entered this field of experimentation. We have, to be sure, the measurements of Richards at comparatively low pressures, and those of Bridgman at much higher pressures, but for only three substances. Except for these measurements, however, there are practically no other data which represent the true compressibility of solids under hydrostatic pressure.

The original object of the authors in starting this investigation was to determine the compressibility of certain rocks and minerals, but preliminary experiments indicated that the method adopted was so satisfactory for solids in general that it seemed worth while to measure the compressibility at high pressures of some of the more common metals and other solids. Accordingly a number of such measurements have been made, and in what follows we describe the method we have used and present the results of our measurements on the compressibility at pressures up to I2,000 megabars of gold, copper, brass, silver, aluminum, zinc, tin, cadmitum, lead, bismuth, a tin-bismuth alloy, sodium chloride, calciumcarbonate, and silica, both crystalline and amorphous.

\section{General Description of Method.}

The sample or test-piece of the material to be investigated is placed in the cylindrical bore of a thick-walled steel cylinder or bomb closed at the bottom and fitted at the top with a movable piston; and in order to transmit a uniform hydrostatic pressure to the test-piece the remainder of the space inside the bomb is filled with a thin liquid which will not solidify or thicken under pressure. If now pressure be applied by forcing the piston downward and simultaneous readings be taken of $(\mathrm{I})$ the piston 
displacement and of (2) the resultant hydrostatic pressure in the liquid, the value of the volume-change of the contents of the bomb as a function of pressure will be obtained. It is obvious that this volume-change is essentially the algebraic sum of three separate changes of volume, viz., that due to ( $\mathrm{r}$ ) the compressibility of the material under examination; (2) the compressibility of the liquid; and (3) the distortion of the bomb and its appurtenances. It remains only to eliminate (2) and (3) and we thus obtain the value of $(\mathrm{I})$, the compressibility of the material. This elimination might be accomplished by separately determining the values of (2) and (3), but it is more convenient as well as more accurate to determine them together by making another similar series of measurements, using a test-piece of known compressibility. We thus, in effect, measure the difference between the compressibility of the solid in question and that of some standard substance the compressibility of which has previously been determined by some more direct means.

Having stated the principle of the method which we have used, we

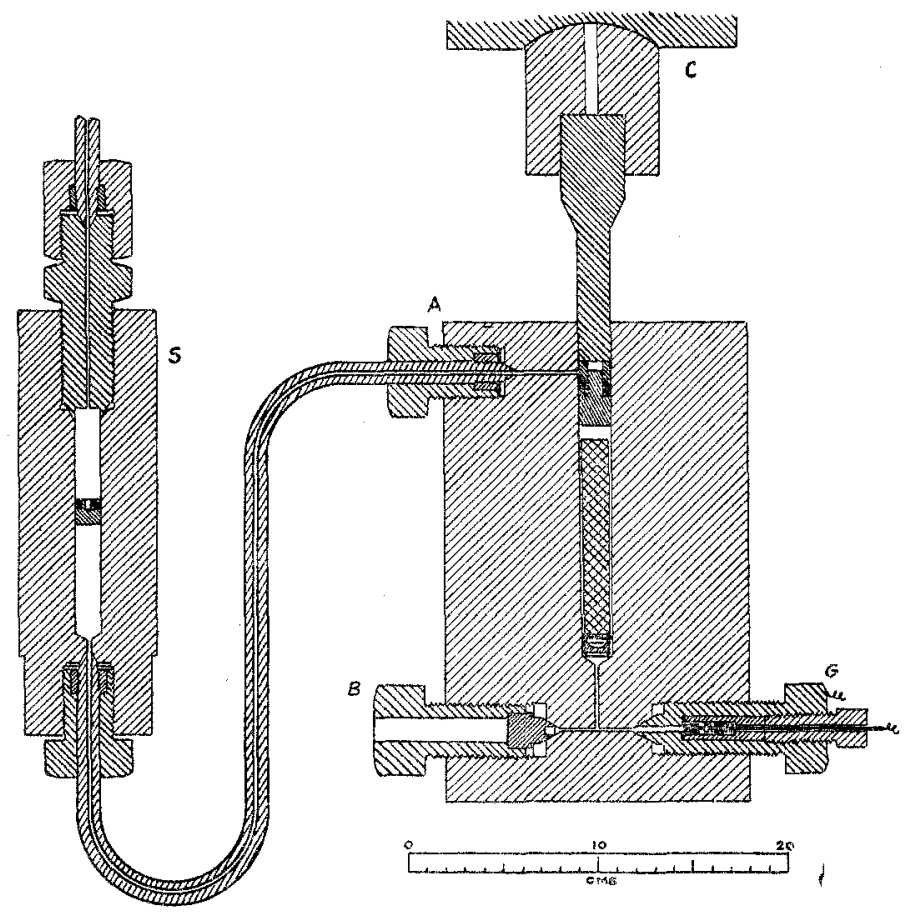

Fig. x.-Diagram of bomb and connections to scale as shown. The specimen to be compressed is placed in the hole in the thick-walled steel cylinder and surrounded with kerosene. The plunger is forced downward by means of a hydraulic press and the pressure thereby produced is measured by means of the resistance-gage G. When the plunger is near the top of its stroke an initial pressure may be applied by pumping liquid through the separator $\mathrm{S}$ and the by-pass $\mathrm{A}$. 
shall now proceed to describe in more detail the various parts of the apparatus, the means employed for the measurement of the pressure and of piston displacement, and the exact procedure followed in carrying out the determination.

The Bomb.-The pressires were produced in a thick-walled cylinder or bomb illustrated in Fig. I. This cylinder is $25^{\circ} \mathrm{mm}$. long and $5_{5}^{\circ}$ mm. in diameter ${ }^{1}$ and is provided with a central hole $17.5 \mathrm{~mm}$. in diameter extending from the top to within $75 \mathrm{~mm}$. of the bottom. The material of the bomb is Halcomb vanadium steel, "Type D," a variety of steel which our own experience has indicated to be superior to all others for

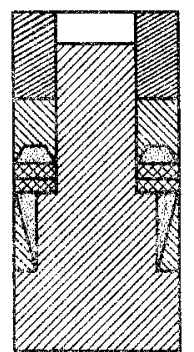

Fig. 2.-Special packing for use in seasoning bomb. As shown in the diagram, which is natural size, a collar of hardened tool., steel fits over the stem of the plug. Below this collar are successively: a collar of soft steel; cupped and filled with solder; two rubber washers; and finally, an inner and outer ring, respectively, of solder and copper. safely withstanding extreme pressures. In order to develop maximum strength and toughness in the steel, the bomb after being machined was heated to about $920^{\circ}$ and quenched in water at $40^{\circ}$. Since this variety of steel, especially when in a large piece, never becomes very hard, it is not necessary to anneal it after quenching in order to draw the temper, but on the other hand the bomb was rendered more resistant to internal pressure by subjecting it to the seasoning process recommended by Bridgman. ${ }^{2}$ This was accomplished by closing with suitable plugs all openings in the bomb except that at the top, filling the interior with a mixture of one part of glycerine to two parts of water, inserting a special packing (Fig. 2) in the top and forcing the packing down with a piston so that a pressure of 25,000 megabars $^{3}$ was developed. The bomb undoubtedly yields slowly under pressure at 10,000 or 12,000 megabars the first time pressure is applied to it, but if the pressure be ap. plied in small increments and sufficient time be allowed each time before stepping up the pressure, so that the viscous yield practically disappears, the elastic limit is finally raised to such an extent that a bomb of the size described can withstand a pressure of 15,000 megabars almost indefinitely without a trace of permanent deformation.

1 The outside diameter while larger than necessary- $25 \mathrm{~mm}$. would probably be sufficient-is advantageous for the reason that the extra mass of metal affords a greater heat capacity which was found convenient (vide infra).

${ }^{2}$ P. W. Bridgman, Proc. Am. Acad., 49, 634. (I914).

${ }^{3}$ A megabar is approximately an atmosphere. More exactly, I megabar $=10^{6}$ dynes $/ \mathrm{cm}^{2}$ o $=1.020 \mathrm{~kg} . / \mathrm{cm}^{2} .=0.987 \mathrm{~atm}$. The megabar is a much more rational unit than the atmosphere. Furthermore, the magnitude of the $\mathrm{kg} . / \mathrm{cm}^{2}$. varies with the force of gravity and therefore its absolute value changes with the geographical locality. For these reasons and also because of its greater convenience in many calculations, we have adopted the megabar as our unit of pressure. 
The bomb rests on the fixed lower platen of a 500-ton hydraulic press, as shown in the photograph (Fig. 3). For the way in which the upper movable platen bears against the piston Fig. I may be consulted. Attention is directed to the curved surfaces $\mathrm{C}$ of contact between the upper platen and the piston and also on the bottom platen. An effective centering of bomb and piston with respect to the press has proved to be an essential requirement for the attainment of extreme pressure. By means of the curved surfaces shown the bomb automatically centers itself,

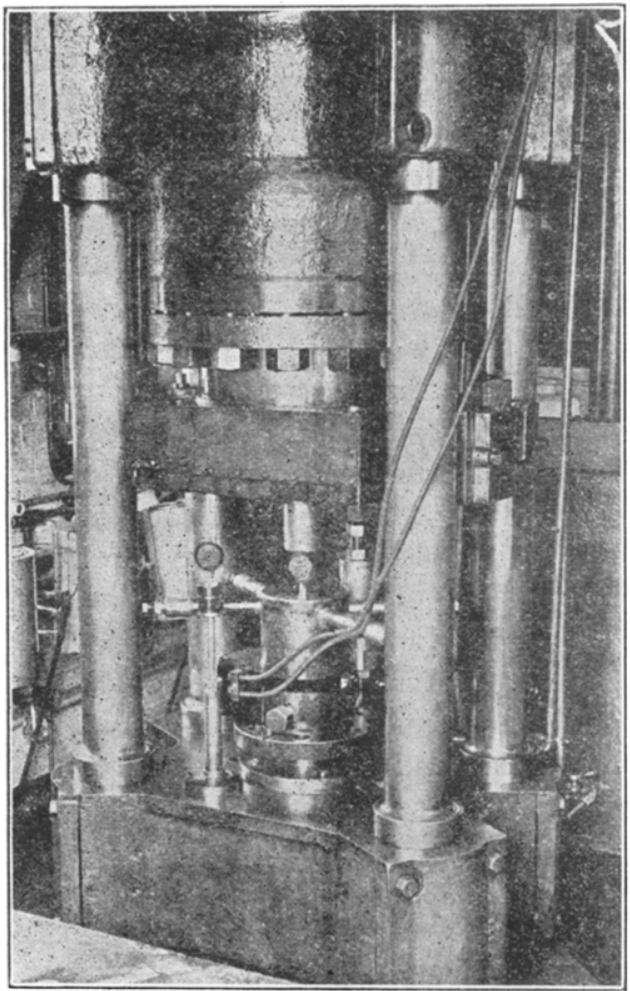

Fig. 3.-Photograph of hydraulic press, bomb, and connections. provided only that the piston has penetrated a certain distance, say one or two centimeters, into the bomb. To steady the bomb at such times as this condition is not fulfilled, there are provided 4 iron rods or supports extending from the bomb to each of the 4 posts of the press and fitted with adjusting screws to facilitate their proper placing.

The packing of the piston is an important part of the apparatus, since success depends to a considerable extent on having a packing which shall be absolutely free from leak and which at the same time shall move in the hole in a regular manner and with minimum friction. The packing regularly used is shown in Fig. 4. It will be noted that for the sake of convenience in manipulation the packing is made a separate part and is not attached to the plunger. Its design, together with that of one of the types of pressure gages to be mentioned later, is practically identical with those already described by Bridgman. ${ }^{1}$ The essential feature of this type of packing, as pointed out by Bridgman, is the unsupported area above the central stem, by virtue of which the hydrostatic pressure in the rubber disk $\mathrm{S}$ is greater than in the bomb, thus removing any tendency for the liquid in the bomb to leak out past the packing. By referring

${ }^{1}$ P. W. Bridgman, Proc. Am. Acad., 49, 631 (1914). 
to Fig. 4, it will be seen that the packing consists of a plug terminating above on a stem in which are fitted 5 washers and a collar. The washers are all I.5 mm. thick and are successively a copper one soldered to the plug, two of soft rubber, another of copper, and finally one of annealed "Type D" vanadium steel. The first copper is made a tight fit in the hole of the bomb; the other copper and the steel washer are made a loose fit on the stem and a push fit in the hole. The collar is made of tool steel hardened and drawn to a dark blue color, and is a loose fit both inside and out, while the plug itself is made of "Type K" vanadium heated to $850^{\circ}$, quenched in oil and annealed long enough at $200^{\circ}$ to remove strains (about one hour). The rubber washers are made slightly larger than

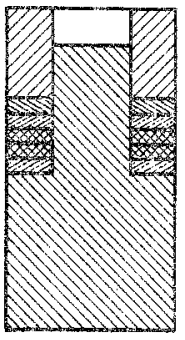

Fig. 4. - Natural size.) Packing regularly, used to make movable piston pressuretight. Over the stem of the plug are successively, beginning at the top, a hardened steel collar, a soft steel washer, a copperwasher, two of rubber, and another of copper. the space they are intended to fill and are cut to a uniform size by means of a simple punch.

The piston is made in two parts as indicated in the diagram (Fig. I). The lower part or piston proper, of tool steel hardened and drawn to a straw color, was driven into the upper part which is of soft machine steel. This arrangement not only effects a saving of steel but also facilitates the repair of a damaged piston.

Besides the central hole in the bomb there are 4 other openings. Of the two lower openings shown in Fig. $x$, one is used to connect with one of the "therlo" pressure gages described below; the other was not ordinarily used for the present work and was closed by a plug, ${ }^{1} \mathrm{~B}$, which is shown in the lower left-hand part of the bomb in Fig. I. The plug consists of two parts: a nut and a small cylinder with a conical end which fits into a conical hole in the bomb. Both parts were made of "Type $\mathrm{K}$ " vanadium steel heat-treated in the same manner as was the plug of the packing (vide supra). A third opening not visible in Fig. I but shown in Fig. 6 (a section perpendicular to that of Fig. I) held the other pressure gage.

The upper opening $A$ of the bomb (Fig. $\mathrm{I}$ ) formed a by-pass by means of which liquid from an ortside source could be pumped into the bomb whenever the piston was at the top of its stroke. This by-pass is practically identical with that used by Bridgman ${ }^{2}$ for a similar purpose, and consists of a hole about $4 \mathrm{~mm}$. in diameter which is tapped and then filled with a suitable screw, along which is filed a groove which is about one $\mathrm{mm}$. wide except for one or two mm. at the inside end where it is merely a fine scratch.

1 See also John Johnston and L. H. Adams, "The Influence of Pressure on the Melting Points of Certain Metals," Am. J. Sci., [4] 3I, 50I-5I7 (r9ri).

"P. W. Bridgman, Phys. Rev., 3, I3I (1914). 
Connection between the by-pass and the pump was made by a separator, S, the construction of which will be evident from a study of Fig. $\mathrm{I}$. The same pump which was described in a former publication ${ }^{1}$ was used for forcing liquid through the by-pass, and since the bomb was filled with kerosene, while a heavier paraffin oil was used with the pump, some sort of device was necessary to transmit the pressure and at the same time prevent the two liquids from mixing. The separator referred to has proven entirely satisfactory for this purpose. The movable part is a cylindrical steel piece having a short stem at one end on which one or two rubber washers are placed. The large opening at the top is closed by a nut with a conical end. This simple device for closing openings at least $15 \mathrm{~mm}$. in diameter has given perfect satisfaction at pressures up to 4000 megabars and would probably be equally effective at much higher pressures.

The Pressure Gage.--For the measurement of the pressure inside the bomb advantage was taken of the change of electrical resistance of a metallic wire when exposed to pressure. Lisell ${ }^{2}$ first made use of the change of resistance of manganin for measuring pressures and subsequently Bridgman ${ }^{3}$ has used the manganin pressure gage with great success up to 20,000 megabars. We have used both manganin and "therio," an alloy similar to manganin in many of its properties, but since "therlo" shows a very low thermo-e. m. f. against copper it is somewhat more suitable for the present purpose than manganin.

The gage coils were made as follows: a length corresponding to about xoo ohms of $0.08 \mathrm{~mm}$. silk-covered therlo wire was wound on a small, brass rod previously covered with a layer of thin waxed paper. A light coating of shellac varnish was applied and when the shellac had partially dried the coil was slipped off the rod and heated in an oven at $140^{\circ}$ for To hours. This treatment served to bake the shellac so hard that the wire held together as a rigid, hollow cylinder and also served to season the wire to temperature. This temperature seasoning was found to be necessary as is also a seasoning to pressure; that is, the resistance changes under pressure are uncertain and irregular until after the coil has been first annealed and then exposed to pressure a few times.

In order to use this coil for the measurement of pressure it is obvious that an electrically insulated and pressure-tight connection through the wall of the bomb is required. During the earlier part of the investigation the pressure gage used was the one shown at G, Fig. I. The method of construction is shown on a large scale in Fig. 5. A cylindrical piece of

"John Johnston and L. H. Adams, "The Effect of Pressure on the Melting Point of Certain Metals," Lac. cit.

2 Lisell, Diss. Upsala, r9o3.

3 P. W. Bridgman, Proc. Am. Acad., 47, 336 (19x). 


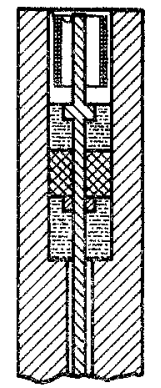

Fig. 5.-Detailed drawing (full size) of inner part of gage shown at G, Fig. I. The small central rod through which current to the coil is conducted is "packed" by means of two cylinders of serpentine rock ("soap-stone") between which is a third cylin. der of rubber.

hardened vanadium steel is made a close fit in the hole in the large nut and is held down by a smaller nut as shown in Fig. I. The current connection consists of a hardened rod likewise of vanadium steel, and $1.5 \mathrm{~mm}$. in diam. except for a shoulder $4 \mathrm{~mm}$. in diam. near one end. The packing fits in a hole $6 \mathrm{~mm}$. in diam. and consists of two cylinders of serpentine rock (sometimes called soapstone) 4 and $6 \mathrm{~mm}$. long, respectively, between which is a cylinder of rubber $5 \mathrm{~mm}$. long. A thin, steel ring is fitted over the central rod just above the lower cylinder of serpentine in order to prevent the rubber from blowing out past the rod. The therlo coil is placed in the upper end of the cylinder and one of its encis connected to the insulated rod while the other end was fastened to the steel cylinder. All connections were made with hard solder (two parts of brass to one of silver) using borax as a flux. In order to facilitate the soldering of the very fine $(0.08 \mathrm{~mm}$.) therlo wire to the steel parts, the ends of the coil were first joined to short bits of $0.2 \mathrm{~mm}$. platinum wire which were then soldered to the cylinder and rod, respectively. The cylinder which holds the packing is made pressure-tight against the bottom of the hole in which it rests by means of a thin washer of soft steel, against which the cylinder is forced by means of the small nut as shown in the diagram.

While this method of packing by means of a simple thrust might not have been expected to work at high pressures, it was found to give satisfaction at pressures above ro,00o megabars. With this type of gage, however, it proved difficult to repair damaged parts and to replace gage coils with new ones, and accordingly during the later measurements pressures were read with another gauge slightly different from that shown it Fig. $x$. ments.

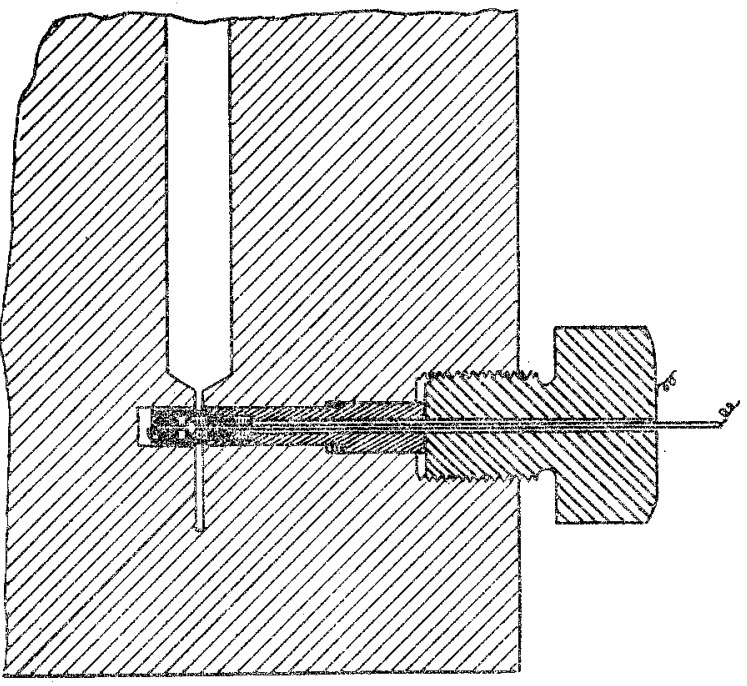

Fig. 6.-( $1 / 2$ natural size.) Section through lower part of bomb (at right angles to the section shown in Fig. I) to show location of pressure gage used for later measure. 
Here the cylinder holding the coil fits directly into a hole in the bomb. As may be seen by referring to Fig. 6 it is made pressure. tight in the hole by means of a tapered shoulder on the cylinder, between which and a square shoulder in the hole are successively, beginning with the outside, a soft steel washer I.5 mm. square in cross-section, a lead washer of the same size and another soft steel washer $0.8 \mathrm{~mm}$. thick.

The therlo gages were calibrated up to 500 megabars by comparison with an absolute gage of the Amagat type. A second absolute gage for calibration at higher pressure was constructed but unfortunately this gage is not yet in perfect working order and hence for the calibration at higher pressures we were obliged to use certain transformation points for our pressure scale. At $20^{\circ}$ the I-II inversion of carbon tetrachloride takes place at 3275 megabars, water freezes at 8830 megabars and mercury freezes at I $430 .{ }^{1}$ These fixed points, together with the absolute gage calibration up to I5oo megabars afford a pressure scale which is sufficiently accurate for the present purpose.

The change of resistance of the therlo coil was measured by means of a type of Wheatstone bridge with 4 equal fixed arms. This is shown. diagrammatically in Fig. 7 in which $G$ represents the gage coil of roo ohms and $\mathrm{F}$ a coil of nearly the same resistance identical in every way with $G$ but placed in a small hole in a steel block which was fastened to the outer end of the gage holder. The object of this was to have the two coils exposed to as nearly the same temperature and heating effect of the current as possible, and to further this object $F$ was also surrounded by kerosene. The bridge is completed by the roo-ohm coils $p$ and $q$ which should be kept at the same temperature (not necessarily equal to that of $G$ and $F$ ).

In this type of bridge the usual galvanometer is replaced by a potentiometer. Now it is obvious that a change in resistance of the gage coil will cause a change in the e. m. f. E indicated by the potentiometer and therefore the value of $E$ may be used as a measure of this change of resistance. In actual practice this method of measuring the change in resistance of pressure-gage coils has proved to be convenient and accutate. It does away with moving contacts in the bridge circuit and for work in which a potentiometer must be used anyway it avoids a multiplicity of instruments.

The form of bridge, unlike the usual Wheatstone bridge, requires a constant current. This is secured by balancing the bridge current against the potentiometer current. Referring to Fig. 7 it is evident that by closing the $\mathrm{K}$ and making the indicated connection to the potentiometer galvanometer, the current through the bridge may be adjusted by means of the rheostat until the drop in potential across $M$ is equal to that across

:P. W. Bridgman, Proc. A m. Acad, 47, 391, 392, 416, 518 (I9II). 
N. The bridge current will then bear a fixed relation to potentiometer current and if the latter be maintained constant by the usual cadmium cell adjustment obviously the bridge current will also be constant. As a matter of fact, if the potentiometer be used solely for resistance measurement, it is not necessary that the bridge current be constant but merely that it bear a fixed relation to the current through the potentiometer.

The potentiometer which was used is a so-called double potentiometer, ${ }^{1}$ and is well adapted for these kinds of adjustment. One set of its dials was regularly used for temperature measurement (e. m. f. of a thermoelement) and the other for pressure measurement (change in resistance of

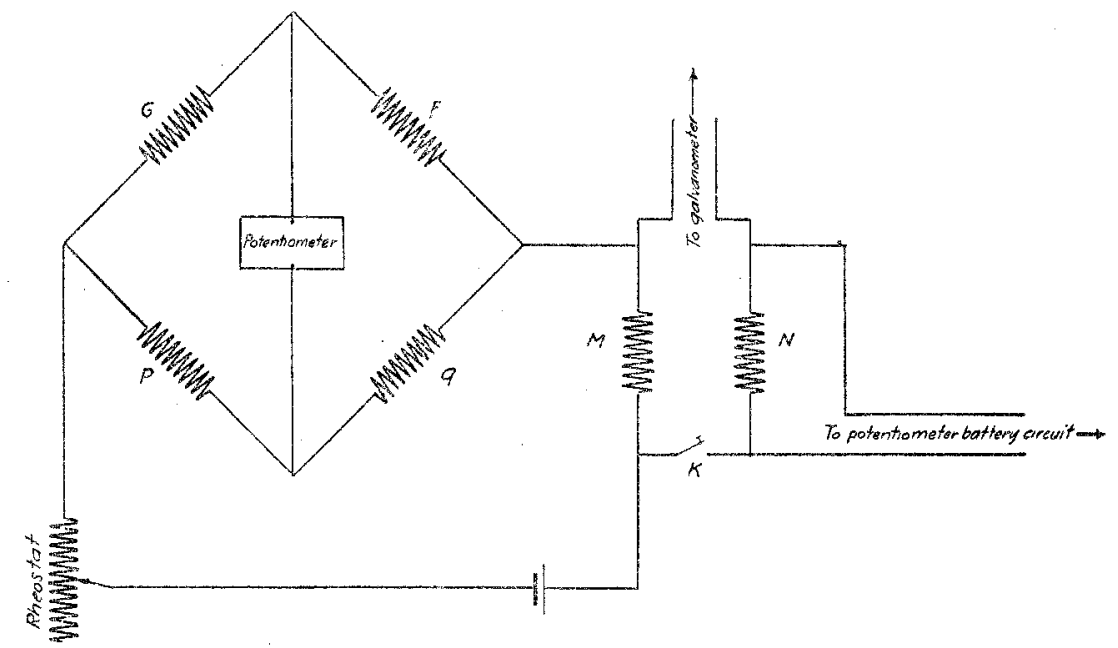

Fig. 7.-Diagram of bridge connections used for measuring changes in resistance of therlo pressure gage. The gage coil $\mathrm{G}$ forms a Wheatstone bridge with 3 fixed coils, F, $p$ and $q$. A variation in the resistance of $G$ gives rise to an e. m. $f$. which is read by the potentiometer and which is a measure of the resistance-change. Constancy of current through the bridge is obtained by equalizing ( $\mathrm{I}$ ) the drop in potential across $M$, a coil in series with the bridge, and (2) the drop across the coil $N$, which is in the potentiometer battery circuit.

a therlo coil). A third position of the controlling knob caused the terminals of $\mathrm{M}$ and $\mathrm{N}$ to be connected directly to the galvanometer and thereby allowed a very rapid adjustment of the bridge current to be made.

In using the bridge it is convenient to so adjust it that the e. m. f. $E$ shall be zero at zero pressure. This was accomplished by inserting in series with $\mathrm{F}$ a mercury resistance which consisted of a glass U-tube containing mercury. The arms were of the same length but of unequal size, the inside diameter of one being I.5, and that of the other about $6 \mathrm{~mm}$.

' For a detailed description of the instrument actually used, see W. P. White, Z. Instrumentenk., 34, 71, 107, 142 (1914). 
The mercury columins could be displaced by copper rods fitting loosely inside the tubes and a coarse and fine adjustment of resistance obtained. It proved possible with this simple device to regulate the resistance at will to within $0.000 \mathrm{r}$ ohm.

It is also convenient, although not essential, to have a third coil similar to $G$ and $F$ and mounted in the same small block with $F$. By means of a simple link-and-cup switch $\mathrm{G}$ could be replaced by this coil, and in case of accidental electrical leaks or short circuits in the system, the source of the trouble could be more easily located.

To determine the relation between the change of resistance of $\mathrm{G}$ and the e. $m$. f. registered by the potentiometer we may proceed as follows:

Let $r, r^{\prime}$, $a r$ and $a r^{\prime}$ be the resistance of the coils G, F, $p$ and $q$, respectively, and let $E$ be the e.m. f. as read by the potentiometer when $r$ is increased to $r+\Delta r$, and $I$ the (constant) total current through the bridge.

Then it can readily be shown that

$$
E=a I r^{\prime} \Delta r /\left\{\left(r+r^{\prime}\right)(a+\mathrm{I})+\Delta r\right\} .
$$

If the coils be equal then, $r=r^{\prime}$ and $a=\mathrm{I}$ and our formula becomes

$$
E=\operatorname{Ir} \Delta r /(4 r+\Delta r) \text {. }
$$

Moreover, if $\Delta r$ be a small quantity when compared to $4^{r}$, the following relations are approximately correct:

$$
\begin{gathered}
E=I \Delta r(\mathrm{r}-\Delta r / 4 r) \\
\Delta r / 4^{r}=(E / I r)+(E / I r)^{2}
\end{gathered}
$$

Substituting in Equation $4, r=100 \mathrm{ohms}, I=20,000$ microamperes,

$$
\Delta r / r=2 \cdot 10^{-6}\left(E+0.5 \cdot 10^{-6} E^{2}\right)
$$

when $E$ is expressed in microvolts.

Thus $E$ is nearly proportional to $\Delta r / r$; more exactly $E$ plus a small correction factor $\left(0.5 \times 10^{-6} E^{2}\right)$ is equal to a constant times $\Delta r / r$. In the actual measurement of pressure, however, $\Delta r$ was not calculated. It is sufficient to determine $E$ as a function of the pressure $P$ by calibration against an absolute gage or by means of fixed points as indicated above, and to then read off the appropriate values of $P$ from a suitable table or graph. It is somewhat more convenient in doing this to plot or calculate $E+0.5^{\circ} \cdot \mathrm{IO}^{-6} E^{2}$ as a function of $P$, since $\Delta r$ is-at least for pressures above 3000 megabars - a linear function of $P$.

Since the pressure coefficient of therlo is about $2.2 \times \mathrm{IO}^{-6}$ per megabar, one microvolt corresponds to about one megabar, and since with our potentiometer and galvanometer $E$ could easily be read to one microvolt or better, we were thus able to read the pressure in our apparatus to within one megabar at any pressure. ${ }^{1}$

1. This does not mean that the absolute accuracy of the pressure readings is one megabar. Indeed, at ro,ooo megabars the uncertainty in the pressure scale is at present probably as much as 20 or 30 megabars. 


\section{Measurement of Piston Displacement.}

The vertical movement of the piston indicates the change in volume of the contents of the bomb. This displacement of the piston was measured by means of Ames dial micrometers. This type of direct-reading micrometer registers the motion of the stem relative to the main body of the gage. Fractions of a revolution are indicated by the large hand and whole revolutions by the small hand. Each division in the dial corresponds to $0.01 \mathrm{~mm}$. and the hand performs one complete revolution per millimeter. Two of these micrometers were used. One of them (which we shall call micrometer I) was attached to the upper press-platen and made contact below with an adjustable pedestal resting on the lower platen. (See Fig. 3.) The other (micrometer II) was fastened to the upper part of the piston by means of an adjustable ciamp and set-screw at such a height that the stem pressed against the top of the bomb. Micrometer II was the one regularly used for measuring the motion of the piston and did not necessarily occupy the same position relative to the bomb from one series of measurements to another. Micrometer I, on the other hand, was used for determining the absolute position of the piston and also served at times as a check on the other micrometer. The micrometers were read to $0.001 \mathrm{~mm}$. but of course the absolute accuracy is not so high as this would indicate.

In order to increase the range of the instruments, which is about $\times 2.8$ mm., disks of steel, case-hardened and accurately ground, were inserted when necessary beneath the stem of the micrometer. A series of 3 disks, respectively 10,20 , and $30 \mathrm{~mm}$. thick, was used with Micrometer $I$, while one disk $10 \mathrm{~mm}$. thick was ordinarily sufficient for II. The micrometers were calibrated by comparing them with a screw-micrometer of known accuracy.

\section{Materials Used.}

Soft Stee1.-This, our standard of reference, was obtained from a piece of "cold rolled" steel bar (Bessemer steel). The carbon content was known to be about $0.2 \%$; d. at $19^{\circ}=7.835$.

Tool Steel.-From a piece of drill rod. The carbon content was not determined but steel was known to contain about $0.8 \% \mathrm{C}$. Its density was 7.795 at $26.1^{\circ}$.

Gold.-Obtained from Handy and Harmon; d. at $24.7^{\circ}=19.22$.

Silver.-The silver which we used was obtained from the U. S. Mint at Philadelphia and was undotibtedly very low in impurities. Its density, determined by the immersion method, was 10.493 at $25^{\circ}$.

Cadmium,-From the J. T. Baker Chemical Co.; d. at $25^{\circ}=8.64$ I.

Lead.-Sample of test lead from Pennsylvania Smelting Company; d. at $26^{\circ}=\mathrm{Ir} .33^{6}$. 
Aluminum.-From a commercial rolled bar; d. at $28.9^{\circ}=2.704$. An analysis showed $0.235 \% \mathrm{Si}$, and $0.016 \% \mathrm{Fe}$.

Copper.-This was from a piece of commercial copper bar. Its purity is possibly open to question, since its density, 8.893 at $25.5^{\circ}$, is somewhat low.

Zinc.-Obtained from Kahlbaum; d. at $25^{\circ}=7.134$.

Brass.-From a piece of commercial rolled bar. An analysis ${ }^{1}$ shows it to contain: $\mathrm{Cu}, 6 \mathrm{r} 76 \% ; \mathrm{Zn}, 35.92 \% ; \mathrm{Pb}, 2.26 \% ; \mathrm{Fe}, 0.05 \%$. Density at $26_{.1} I^{\circ}=8.464$.

Tin.-Obtained from Kahlbaum; d. at $25^{\circ}=7.282$.

Bismuth.-This was obtained from the Baker and Adamson Chemical Works. Its density at $25^{\circ}$ was 9.806 .

Tin-Bismuth Alloy.- This alloy was made up to be near the eutectic in composition. By analysis it was found to contain $53.8 \% \mathrm{Bi}$ and $45.6 \% \mathrm{Sn}$; d. at $28.7^{\circ}, 8.569$.

Calcite.-The calcite test piece was taken from a large, colorless crystal from Lampassas County, Texas; d. at $25.2^{\circ}=2.7 \mathrm{Ir}$.

Sodium Chloride.-Taken from a large crystal of halite; d. at $25.2^{\circ}=$ 2.163.

Quartz.-This was from a large crystal of clear, colorless quartz, kindly furnished by Dr. George P. Merrill of the National Museum. Its density at $25^{\circ}$ was 2.648 .

Fused Silica Glass.-This was from a piece of laboratory capillary tubing about $18 \mathrm{~mm}$. in diameter with a one mm. hole. The glass was somewhat translucent due to the presence of numerous fine capillary holes running in a direction parallel to the larger dimension of the rod. 'The density, 2.135 at $26^{\circ}$, is about $3 \%$ lower than the density of clear silica glass as determined by Day and Sheperd ${ }^{2}$ and this indicates about $3 \%$ of pore spaces. For this reason not much weight can be attached to results here obtained for the compressibility of silica glass. On the other hand, since the pore space as determined by the immersion method consists of "closed pores" and since these pores are very fine, it is possible that compressibility of the clear homogeneous glass would not be materially lower than our result.

Preparation of Test Pieces.-For convenience in subsequent calculations all of the test-pieces were made to have approximately the same volume. Their shape was cylindrical, the diameter being about 15.8 mm., the length about $101.7 \mathrm{~mm}$. The volume which was thus about 20 cc. was carefully determined (after each cylinder had been subjected to high pressure) by measuring the apparent loss of weight in water. The

${ }^{3}$ For assistance with this analysis we are indebted to Dr. E. G. Zies of this laboratory.

"Arthur I. Day and E. S. Shepherd, Am. J.Sci., 22, 276 (1906). 
test pieces of steel, copper, brass and aluminum were made from round bars of commercial stock by turning in a lathe. The cylinders of tin, silver, bismuth, zinc, cadmium, tin-bismuth alloy, lead, and gold were cast in a horizontal graphite motild, hammered with a heavy sledge, and turned down to size. In the case of calcite, sodium chloride, quartz and silica glass a piece of the material of proper size was first ground roughly to size by hand, and then placed in a grinding machine where they were given their true cylindrical form.

Experimental Procedure.- The bomb, having been set in place, was partially filled with kerosene, the test-piece introduced and the air removed by evacuation with a rotary vacuum pump. The separator was then connected and the pressure gage adjusted, after which more kerosene was added and the packing inserted. The piston was then placed on the packing, forced down by means of the press until the top of the packing was 3 or $4 \mathrm{~mm}$. below the top of the bomb, and kerosene pumped through the by-pass and into the bomb until a pressure of about rooo megabars was reached. The object of this preliminary pumping was merely to facilitate the removal of the packing when the measurements had been completed. As the piston was again forced downward, the packing moved down below the by-pass, which then ceased to play any part during the course of the measurements.

The piston was advanced at such a rate that the pressure increased about rooo megabars per minute until a pressure of 12,500 was reached. ${ }^{1}$ After the apparatus had stood at this pressure for 20 minutes the series of readings was begun. The observations were made with decreasing pressure for the reason that there is considerable deformation of the packing the first time that pressure is applied to it, so that the apparent volume change of the contents of the bomb may be irregular, and uncertain.

A pair of readings, one of the pressure gage and one of the micrometer (II) was taken at each Iooo megabars between 12000 and 2000 inclusive. ${ }^{2}$ At 2000 megabars an additional observation was made of the reading of Micrometer I. This fixes the absolute height of the piston corresponding to a definite pressure and thus determines the amount of kerosene in the bomb. The necessity of this will be referred to later on. The time interval between readings was uniformly 6 minutes, which was found by trial to be sufficiently long to allow the heat of compression to be dissipated and the pressure to become steady. For convenience in calculation the pressure readings were taken as close to the even 1000's as

I In some of the earlier series of measurements the maximum pressure reached was 8500 megabars.

${ }^{2} 8000$ to 2000 inclusive in the earlier measurements; when readings were taken at the even $1000 \mathrm{~kg} . / \mathrm{cm}^{2}$. 
practicable. By reason of the ease and rapidity with which the pressure gage could be read no difficulty was experienced in securing pressure readings which differed from the even rooo's by less than ro megabars.

When the pressure was lowered preparatory to taking a reading it was found advisable to drop it about 50 megabars below the proper point and then to raise the pressure slowly until the desired pressure was reached. On account of the friction in the packing, its motion is slightly more regular with increasing pressure than with decreasing pressure and this procedure of "taking in the slack" was found to increase the accuracy of the readings. The readings were discontinued at 2000 megabars partly for the reason that since our main interest was in the compressibility at high pressures, the readings at lower pressures were of less importance; and partly because of irregularities which may occasionally be introduced at pressures of only a few hundred megabars on account of a small amount of air remaining in the bomb. Nevertheless it now appears probable that determinations by this method at pressures as low as rooo megabars would be trustworthy.

After the series of measurements had been completed the piston was allowed to rise until the packing was above the by-pass, when, by admitting kerosene under pressure through the by-pass the packing was easily blown out. The friction of the packing when near the top of the bomb was approximately $45^{\circ}$ megabars; in other words, when the piston is removed the packing ceases to move as soon as the pressure has fallen to $45^{\circ}$ megabars, and this amount of pressure must be applied in order to blow it out.

Supposing now that one or more sets of pressure-volume readings have been obtained for each of the materials under investigation, the next step is to calculate from these data the true compressibility, with reference to that of the standard-soft steel.

\section{Experimental Results and Method of Calculation.}

In order to determine the changes of volume under pressure of a given substance by the present method, two series of pressure-volume readings are required-one with the test piece of the substance in the bomb and another similar series with a test piece of known compressibility. We thus, in effect, measure the difference in compressibility of the two materials. Soft steel has been chosen as our standard of reference. Bridgman has measured the compressibility of soft steel by a direct method ${ }^{1}$ and has found the volume change to be proportional to the pressure up to $10,000 \mathrm{~kg} . / \mathrm{cm}^{2}$. The compressibility at $\mathrm{IO}^{0}$ is $0.583 \cdot 1 \mathrm{O}^{-6}$ per $\mathrm{kg} . / \mathrm{cm}^{2}$; and $50^{\circ}, 0.60 \mathrm{r} \cdot 10^{\circ}$. At room temperatures, say $20^{\circ}$, the compressibility would therefore by linear interpolation be $0.587 \cdot 10^{-6}$ per $\mathrm{kg} . / \mathrm{cm}^{2}$; ; or $0.598 \cdot 10^{-6}$ per megabar.

I P. W. Bridgman, Proc. Am. Acad, 47, 366 (Igri). 
Grüneisen ${ }^{1}$ has measured the compressibility of steel by an indirect (Mallock's) method and has found $0.58 \cdot 10^{-6}$ and $0.63 \cdot 10^{-6} \mathrm{~cm}^{2} . / \mathrm{kg}$. for two different samples. In our calculations we have assumed $0.60 \cdot 10^{-6}$ per

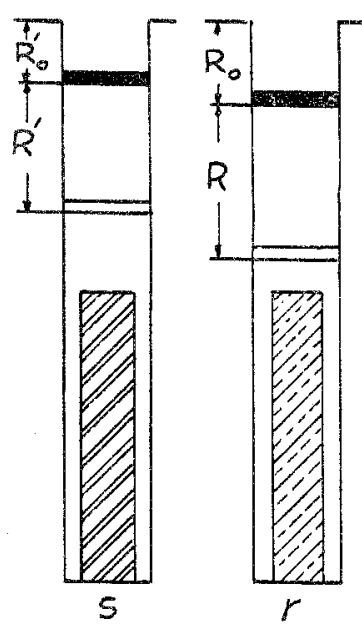
megabar to be the compressibility of soft steel.

The compressibility of the kerosene used in the bomb occurs as a correction factor in the formula given below, and was determined from two series of readings, one with the steel cylinder in the bomb, and the other series with kerosene alone.

Fig. 8 illustrated the positions of the piston for $s$ the comparison substance and $r$ some other material. The difference in levels at a fixed initial pressure, $P_{0}$, is $R_{0}-R_{0}^{\prime}$, and $R^{\prime}$ and $R$ are the piston displacements from $P_{0}$ to $P$ for $s$ and $r$, respectively. The difference in volume at the pressure $P$ is equal to $\left(\Delta R_{0}+R-R^{\prime}\right) A$ $(\mathrm{I}+\alpha P$ ) where $A$ is the cross section of the hole Fig. 8.-Sketch (for use in at $P=0$ and $\alpha$ is the pressure coefficient of $A$. connection with description Equating this value to the difference as obtained of method of calculation) by subtracting the volumes of the substances in showing initial and final the two cases, we have of the two substances $r$ and $s\left(\Delta R_{0}+R-R^{\prime}\right) A(\mathrm{I}+\alpha P)=V_{s}\left(\mathrm{I}-\Delta v_{s}\right)+$ whose compressibilities are $V_{k}^{\prime}\left(\mathrm{I}-\Delta v_{k}\right)-V_{r}\left(\mathrm{I}-\Delta v_{r}\right)-V_{k}\left(\mathrm{I}-\Delta v_{k}\right)$ being compared.

in which $V$ is the volume at $P_{0}$ of the substance indicated by the subscript ( $k$ is the liquid used to transmit pressure), and $\Delta v$ is the change of volume of one cc. of the indicated substance between $P_{\mathrm{o}}$ and $P$. Since

$$
V_{s}-V_{r}+V_{k}^{\prime}-V_{k}=A\left(\mathrm{x}+\alpha P_{0}\right) \Delta R_{0}
$$

our formula becomes,

$$
\begin{aligned}
\left(\Delta v_{r}-\Delta v_{s} V_{s} / V_{r}\right) V_{r} / A= & \left(R-R^{\prime}\right)(\mathrm{r}+\alpha P)+\alpha \Delta R_{0}\left(P-P_{0}\right) \\
& +\Delta v_{k}\left[\Delta R_{0}(\mathrm{I}+\alpha P)+\left(V_{r}-V_{s}\right) / A\right]
\end{aligned}
$$

This is the torm which we found most convenient for calculating the required change of volume ${ }^{2}$ of the substance between the pressures $P$ 。 and $P$.

It should be noted that $\Delta v_{r}$, as obtained from (6) in the form given, is the change of volume of the substance between $P_{0}$ and $P$ per cc. of the substance at $P_{0}$. If it is desired to refer the volume changes to one cc, of the substance at atmospheric pressure, for $V_{r}$ occurring outside the

1. E. Grüneisen, Ann. Phys., [4] 33, 1262 (19ro).

2 This formula is practically the same as one used by Bridgman in measuring the compressibilities of liquids. Proc. Am. Acad., 48, 326 (r912). 
parentheses on the left-hand side of Equation $6 V_{1}$, the volume of the substance at $P=$ I must be substituted.

In determining the value $\Delta v_{k}$ of the kerosene which we used for transmitting pressure, we put $V_{r}$ in Equation 6 equal to zero and obtain

$$
\begin{aligned}
\Delta v_{s}\left(V_{s}-A \Delta R\right)-V_{s} \Delta v_{s}= \\
A\left(R-R^{\prime}\right)(I+\alpha P)+A \alpha \Delta R_{0}\left(P-P_{0}\right)
\end{aligned}
$$

from which $\Delta v_{k}$ can be calculated for use in Equation 6.

By making the volume of the samples as nearly equal as possible and by using as nearly as possible the same volume of kerosene in each case it is possible to cut down the terms on the right-hand side of Equation 6 with the exception of the first. As our measurements of piston displacement were made to o.oor mm., the correction terms were calculated to the same figure. While our probable accuracy was not so great as this, our restits in many runs were self-consistent to better than $0.01 \mathrm{~mm}$.

The change of volume under pressure of one sample of our kerosene is shown in Table $\mathrm{I}$.

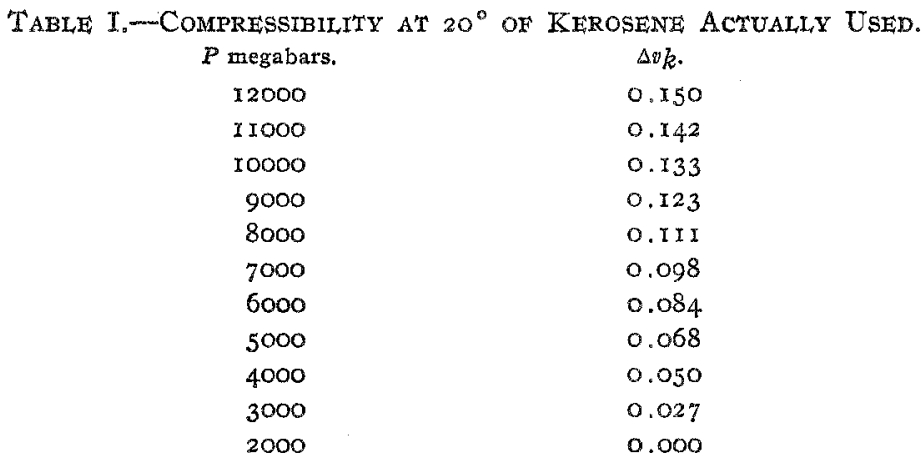

The maximum value of $\Delta v_{k}$ is o.r 5 , so that in the calculation of compressibilities by (6) $V-V_{s}$ had to be known to better than $2 \mathrm{cu} . \mathrm{mm}$. in order that the correction be determined to $0.001 \mathrm{~mm}$.

\begin{tabular}{|c|c|c|c|c|c|c|}
\hline $\begin{array}{l}\text { Pressure. } \\
\text { Megabars. }\end{array}$ & $R-R^{\prime}$ & $R-R^{\prime}(\mathrm{cos}$ & $\begin{array}{r}\Delta v_{r}-\Delta v_{s} \\
\text { QUARTZ }\end{array}$ & $\Delta y_{\gamma}$ (obs.) & $\Delta v_{p}$ (calc.) & $\begin{array}{l}\text { Diff } \times 10^{4} \\
\text { (Obs. }\end{array}$ \\
\hline$\Delta R_{0}=0$. & $V=$ & 5I, $Q$ & $0.06, x 0^{4} a=$ & $0.5, I 0^{6} b$ & $2.622, \mathrm{IO}^{11} \mathrm{C}$ & $=-2.05$ \\
\hline .12000 & $x .493$ & 1.588 & 0.01819 & 0.02419 & 0.02422 & -0.3 \\
\hline$\pi 1000$ & $x .365$ & I. 452 & 1664 & 2204 & 2199 & 0.5 \\
\hline roooo & 1.224 & I.304 & 1494 & I974 & 1972 & 0.2 \\
\hline 9000 & $x .085$ & I. 157 & 1326 & 1746 & 1740 & 0.6 \\
\hline 8000 & 0.930 & 0.994 & II 39 & I 499 & 1503 & -0.4 \\
\hline 7000 & 0.787 & $0,84 \mathrm{I}$ & 964 & 1264 & 1265 & $-0 . I$ \\
\hline 6000 & 0.628 & 0.674 & $77^{2}$ & IOr 2 & IOZI & -0.9 \\
\hline 5000 & 0.490 & $0.5^{25}$ & 602 & 782 & 774 & 0.8 \\
\hline 4000 & 0.320 & 0.345 & 395 & 515 & $52 \mathrm{I}$ & -0.6 \\
\hline 3000 & 0.180 & $0.19 I$ & $2 \times 9$ & 279 & 265 & 1.4 \\
\hline 2000 & 0.000 & 0.000 & 0.00000 & 0.00000 & 0.00005 & -0.5 \\
\hline
\end{tabular}

TABLE II.-RESULTS OF COMPRESSIBIIITY MEASUREMENTS. 
TABLE II (continued).

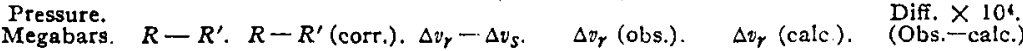
QUARTZ.

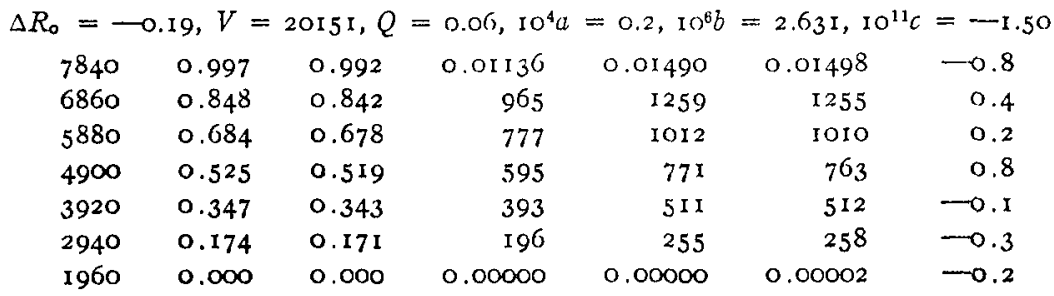

Calcite.

$\Delta R_{0}=-0.63, V=20074, Q=-0.07,10^{4} a=0.8,10^{\circ} \mathrm{b}=1.396, c=0$.

$\begin{array}{rrrrrrr}12000 & 0.812 & 0.712 & 0.00819 & 0.01419 & 0.01404 & \text { I.5 } \\ 11000 & 0.726 & 0.630 & 725 & 1265 & 1264 & 0.1 \\ 10000 & 0.645 & 0.554 & 637 & 1117 & 1125 & -0.8 \\ 9000 & 0.574 & 0.489 & 562 & 982 & 985 & -0.3 \\ 8000 & 0.491 & 0.414 & 476 & 836 & 846 & -1.0 \\ 7000 & 0.419 & 0.351 & 404 & 704 & 706 & -0.2 \\ 6000 & 0.341 & 0.281 & 323 & 563 & 566 & -0.3 \\ 5000 & 0.264 & 0.217 & 250 & 430 & 427 & 0.3 \\ 4000 & 0.192 & 0.151 & 174 & 294 & 287 & 0.7 \\ 3000 & 0.108 & 0.088 & 101 & 161 & 148 & 1.3 \\ 2000 & 0.000 & 0.000 & 0.00000 & 0.00000 & 0.00008 & -0.8\end{array}$

\section{Calcite.}

$\Delta R_{0}=-0.80, V=20074, Q=0.07,10^{4} a=2.7,10^{6} b=1.377, c=0$.

$\begin{array}{rrrrrrr}7840 & 0.511 & 0.414 & 0.00476 & 0.00830 & 0.00837 & -0.7 \\ 6860 & 0.434 & 0.348 & 400 & 694 & 702 & -0.8 \\ 5880 & 0.362 & 0.287 & 330 & 565 & 567 & -0.2 \\ 4900 & 0.299 & 0.239 & 275 & 451 & 432 & 1.9 \\ 3920 & 0.212 & 0.168 & 193 & 311 & 297 & 1.4 \\ 2940 & 0.127 & 0.102 & 117 & 176 & 162 & 1.4 \\ 1960 & 0.000 & 0.000 & 0.00000 & 0.00000 & 0.00027 & -2.7\end{array}$

Aluminum.

$\Delta R_{0}=-0.76, V=20160, Q=0.34,10^{4} a=-1.0,10^{6} b=1.309, c=0$.

$\begin{array}{rrrrrrr}\text { I2000 } & 0.681 & 0.620 & 0.00710 & 0.01310 & 0.01299 & \text { I.I } \\ \text { I } 1000 & 0.615 & 0.555 & 635 & 1175 & 1168 & 0.7 \\ 10000 & 0.540 & 0.483 & 553 & 1033 & 1037 & -0.4 \\ 9000 & 0.470 & 0.418 & 479 & 899 & 906 & -0.7 \\ 8000 & 0.400 & 0.353 & 404 & 764 & 775 & -1.1 \\ 7000 & 0.340 & 0.297 & 340 & 640 & 644 & -0.4 \\ 6000 & 0.275 & 0.238 & 272 & 512 & 514 & -0.2 \\ 5000 & 0.207 & 0.177 & 203 & 383 & 383 & 0.0 \\ 4000 & 0.132 & 0.110 & 126 & 246 & 252 & -0.6 \\ 3000 & 0.066 & 0.056 & 64 & 124 & 121 & 0.3 \\ 2000 & 0.000 & 0.000 & 0.00000 & 0.00000 & -0.00010 & 1.0\end{array}$


TABLF II (continued).

Pressure.

Megabars. $R-R^{\prime} . R-R^{\prime}$ (corr), $\Delta v_{\gamma}-\Delta v_{s} . \quad \Delta v_{\gamma}$ (obs.). $\quad \Delta v_{\gamma}$ (calc.), $\quad$ Diff. $\times$ (Obs. 10 calc.)

AluMinum.

\begin{tabular}{|c|c|c|c|c|c|c|}
\hline 8000 & 0.596 & 0.632 & 0.00723 & 0.01323 & 0.01326 & -0.3 \\
\hline 1000 & 0.544 & 0.576 & 660 & 1200 & II9z & 0.8 \\
\hline 1000 & 0.474 & 0.504 & 577 & xo57 & 1058 & -0.1 \\
\hline 9000 & 0.422 & 0.450 & 5 I 5 & 935 & 924 & I.I \\
\hline 8000 & $0.35 \mathrm{I}$ & 0.374 & 428 & 788 & 790 & -0.2 \\
\hline 7000 & $0.29 \mathrm{I}$ & 0.311 & 356 & 656 & 656 & 0.0 \\
\hline 6000 & 0.222 & 0.239 & 274 & $5 \pi 4$ & $5^{24}$ & - I. . \\
\hline 5000 & $0.15^{8}$ & 0.172 & r97 & 377 & 388 & $-\mathrm{Y} . \mathrm{I}$ \\
\hline 4000 & 0. ror & 0,110 & 126 & 246 & 254 & -0.8 \\
\hline 000 & $0.05 \mathrm{I}$ & 0.056 & 64 & 124 & 120 & 0.4 \\
\hline Doo & 0.000 & 0.000 & 0.00000 & 0.00000 & -0.00014 & I \\
\hline
\end{tabular}

SODIUM CHLORIDE.

$\Delta R_{0}=-0.70, V=19954, Q=-1.04,10^{4} a=0.7,10^{6} b=3.992,10^{11} c=-2.98$.

$\begin{array}{rrrrrrr}\text { I } 2000 & 2.902 & 2.676 & 0.03096 & 0.03696 & 0.03701 & -0.5 \\ 11000 & 2.667 & 2.448 & 2832 & 3372 & 3359 & 1.3 \\ 10000 & 2.395 & 2.186 & 2529 & 3009 & 3010 & -0.1 \\ 9000 & 2.132 & 1.936 & 2240 & 2660 & 2655 & 0.5 \\ 8000 & 1.844 & 1.664 & 1925 & 2285 & 2295 & -1.0 \\ 7000 & 1.565 & 1.404 & 1624 & 1924 & 1928 & -0.4 \\ 6000 & 1.279 & 1.139 & 1318 & 1558 & 1557 & 0.1 \\ 5000 & 0.979 & 0.863 & 998 & 1178 & 1178 & 0.0 \\ 4000 & 0.677 & 0.592 & 685 & 805 & 793 & 1.2 \\ 3000 & 0.350 & 0.301 & 348 & 408 & 403 & 0.5 \\ 2000 & 0.000 & 0.000 & 0.00000 & 0.00000 & 0.00007 & -0.7\end{array}$

SODIUM CHIORIDE.

$\Delta R_{0}=0.24, V=20024, Q=-0.74,10^{4} a=2.0,10^{6} b=4.033,1^{11} c=-2.85$.

$\begin{array}{rrrrrrr}7840 & 1.710 & 1.672 & 0.01926 & 0.02280 & 0.02294 & -1.4 \\ 6860 & 1.456 & 1.42 I & 1637 & 1931 & 1929 & 0.2 \\ 5880 & 1.183 & 1.15 I & 1336 & 1561 & 1558 & 0.3 \\ 4900 & 0.910 & 0.88 I & 1014 & 1190 & 1182 & 0.8 \\ 3920 & 0.629 & 0.609 & 702 & 820 & 800 & 2.0 \\ 2940 & 0.324 & 0.310 & 357 & 416 & 413 & 0.3 \\ 1960 & 0.000 & 0.000 & 0.00000 & 0.00000 & 0.00020 & -2.0\end{array}$

LEAD.

$\Delta R_{0}=-0.17, V=2011 \mathrm{I}, Q=-0.03,10^{4} a=-0.8,10^{4} b=2.215,10^{11} c=-0.21$.

$\begin{array}{rrrrrrr}12000 & 1.388 & \mathrm{I} .376 & 0.01580 & 0.02180 & 0.02186 & -0.6 \\ 11000 & 1.262 & \mathrm{I} .249 & 1434 & 1974 & 1968 & 0.6 \\ 10000 & \mathrm{I} .116 & \mathrm{I} .103 & 1266 & 1746 & 1750 & -0.4 \\ 9000 & 0.993 & 0.980 & 1125 & 1545 & 1530 & 1.5 \\ 8000 & 0.837 & 0.823 & 945 & 1305 & 1313 & -0.8 \\ 7000 & 0.708 & 0.695 & 798 & 1098 & 1094 & 0.4 \\ 6000 & 0.567 & 0.554 & 636 & 876 & 875 & 0.1 \\ 5000 & 0.428 & 0.416 & 478 & 658 & 654 & 0.4 \\ 4000 & 0.267 & 0.259 & 297 & 417 & 433 & -1.6 \\ 3000 & 0.137 & 0.132 & 152 & 212 & 213 & -0.1 \\ 2000 & 0.000 & 0.000 & 0.00000 & 0.00000 & -0.00008 & 0.8\end{array}$


TABIE II (continued).

Pressure.

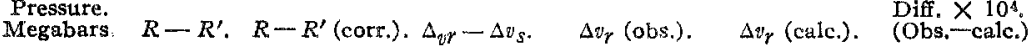

I.AAD.

$\Delta R_{0}=0.93, V=201 \mathrm{II}, Q=-0.03,10^{4} a=0.7,10^{6} b=2.175, \mathrm{IO}^{11} c=-0.38$.

$\begin{array}{rrrrrrr}7840 & 0.682 & 0.796 & 0.00915 & 0.01269 & 0.01273 & -0.4 \\ 6860 & 0.575 & 0.675 & 776 & 1070 & 1064 & 0.6 \\ 5880 & 0.452 & 0.537 & 617 & 852 & 854 & -0.2 \\ 4900 & 0.334 & 0.404 & 464 & 640 & 643 & -0.3 \\ 3920 & 0.221 & 0.273 & 314 & 432 & 432 & 0.0 \\ 2940 & 0.120 & 0.148 & 170 & 229 & 220 & 0.9 \\ 1960 & 0.000 & 0.000 & 0.00000 & 0.00000 & 0.00007 & -0.7\end{array}$

BRASS.

$\Delta R_{0}=0.25, V=20078, Q=0.05, \mathrm{IO}^{4} a=0.5, \mathrm{I0}^{6} \mathrm{~b}=0.875, c=0$.

$\begin{array}{rrrrrrr}12000 & 0.190 & 0.244 & 0.0028 \mathrm{I} & 0.0088 \mathrm{I} & 0.00880 & 0 . \mathrm{I} \\ \text { I1000 } & 0.168 & 0.216 & 248 & 788 & 792 & -0.4 \\ 10000 & 0.144 & 0.189 & 217 & 697 & 705 & -0.8 \\ 9000 & 0.136 & 0.176 & 202 & 622 & 617 & 0.5 \\ 8000 & 0.121 & 0.158 & 182 & 542 & 530 & 1.2 \\ 7000 & 0.097 & 0.129 & 148 & 448 & 442 & 0.6 \\ 6000 & 0.069 & 0.096 & 110 & 350 & 355 & -0.5 \\ 5000 & 0.059 & 0.081 & 93 & 273 & 267 & 0.6 \\ 4000 & 0.036 & 0.051 & 59 & 179 & 180 & -0.1 \\ 3000 & 0.012 & 0.020 & 23 & 83 & 92 & -0.9 \\ 2000 & 0.000 & 0.000 & 0.00000 & 0.00000 & 0.00005 & -0.5\end{array}$

BRASS.

$\Delta R_{0}=0.93, V=20078, Q=0.05,1^{4} a=1.2,10^{6} b=0.912, c=0$.

$\begin{array}{rrrrrrr}7840 & 0.042 & 0.159 & 0.00183 & 0.00537 & 0.00548 & -\mathrm{I} . \mathrm{I} \\ 6860 & 0.05 \mathrm{I} & 0.154 & 177 & 47 \mathrm{I} & 459 & \mathrm{I} .2 \\ 5880 & 0.026 & 0.115 & 132 & 367 & 370 & -0.3 \\ 4900 & 0.017 & 0.090 & 104 & 280 & 280 & 0.0 \\ 3920 & 0.009 & 0.063 & 72 & 190 & 191 & -0.1 \\ 2940 & 0.017 & 0.048 & 55 & 114 & 101 & 1.3 \\ 1960 & 0.000 & 0.000 & 0.00000 & 0.00000 & 0.00012 & -\mathrm{I} .2\end{array}$

Cadmium.

$\Delta R_{0}=0.23, V=20126, Q=0.06,10^{4} G=-1.1,10^{6} b=2.165,10^{11} \mathrm{C}=-2.71$.

$\begin{array}{rrrrrrr}12000 & 1.036 & 1.098 & 0.01259 & 0.01859 & 0.01883 & -2.4 \\ 11000 & 0.985 & 1.042 & 1195 & 1735 & \text { I718 } & 1.7 \\ 10000 & 0.886 & 0.939 & 1077 & 1557 & 1548 & 0.9 \\ 9000 & 0.794 & 0.842 & 966 & 1386 & 1372 & 1.4 \\ 8000 & 0.686 & 0.728 & 835 & 1195 & 1190 & 0.5 \\ 7000 & 0.573 & 0.609 & 697 & 997 & 1004 & -0.7 \\ 6000 & 0.460 & 0.490 & 562 & 802 & 812 & -1.0 \\ 5000 & 0.348 & 0.371 & 426 & 606 & 614 & -0.8 \\ 4000 & 0.225 & 0.240 & 275 & 395 & 411 & -1.6 \\ 3000 & 0.123 & 0.131 & 150 & 210 & 203 & 0.7 \\ 2000 & 0.000 & 0.000 & 0.00000 & 0.00000 & -0.00011 & 1.1\end{array}$


TABLE II (continued).

$\begin{aligned} & \text { Pressute. } \\ & \text { Megabars. }\end{aligned} R-R^{\prime} . R-R^{\prime}$ (corr.). $\Delta v_{\gamma}-\Delta v_{s, *} \quad \Delta v_{\gamma}$ (obs.). $\quad \Delta v_{\gamma}$ (calc.). $\quad$ (Obs. $\times 10^{4}$-calc.

Cadmitum.

$\Delta R_{0}=0.82, V=20126, Q=0.06,10^{4} a=1.2,10^{6} b=2.07 \mathrm{~s}, 10^{11} c=-1.75$.

$\begin{array}{rrrrrrr}7840 & 0.590 & 0.695 & 0.00798 & 0.01152 & 0.01170 & -1.8 \\ 6860 & 0.519 & 0.610 & 700 & 994 & 985 & 0.9 \\ 5880 & 0.420 & 0.498 & 572 & 807 & 797 & 1.0 \\ 4900 & 0.315 & 0.380 & 436 & 612 & 606 & 0.6 \\ 3920 & 0.198 & 0.246 & 282 & 400 & 411 & -1.1 \\ 2940 & 0.118 & 0.145 & 166 & 225 & 213 & 1.2 \\ 1960 & 0.000 & 0.000 & 0.00000 & 0.00000 & 0.00012 & -1.2\end{array}$

ZINC.

$\Delta R_{0}=0.12, V=20077, Q=-0.10, \mathrm{IO}^{4} a=-0.5,10^{6} b=1.697, \mathrm{IO}^{11} c=-\mathrm{r} .69$.

$\begin{array}{rrrrrrr}12000 & 0.776 & 0.793 & 0.00912 & 0.01512 & 0.01523 & -1.1 \\ 11000 & 0.731 & 0.746 & 858 & 1398 & 1385 & 1.3 \\ 10000 & 0.652 & 0.664 & 764 & 1244 & 1244 & 0.0 \\ 9000 & 0.583 & 0.593 & 682 & 1102 & 1100 & 0.2 \\ 8000 & 0.511 & 0.521 & 599 & 959 & 952 & 0.7 \\ 7000 & 0.428 & 0.435 & 500 & 800 & 801 & 0.1 \\ 6000 & 0.344 & 0.348 & 400 & 640 & 647 & -0.7 \\ 5000 & 0.260 & 0.264 & 304 & 484 & 489 & -0.5 \\ 4000 & 0.178 & 0.181 & 208 & 328 & 328 & 0.0 \\ 3000 & 0.088 & 0.088 & 101 & 161 & 163 & -0.2 \\ 2000 & 0.000 & 0.000 & 0.00000 & 0.00000 & -0.00005 & 0.5\end{array}$

ZINC.

$\Delta R_{0}=0.14, V=20077, Q=-0.10,10^{4} a=0.9,10^{8} b=1.636,10^{11} c=-0.84$.

$\begin{array}{rrrrrrr}7840 & 0.494 & 0.505 & 0.00581 & 0.00935 & 0.00942 & -0.7 \\ 6860 & 0.429 & 0.438 & 504 & 798 & 791 & 0.7 \\ 5880 & 0.346 & 0.354 & 407 & 642 & 638 & 0.4 \\ 4900 & 0.259 & 0.265 & 305 & 481 & 483 & -0.2 \\ 3920 & 0.176 & 0.180 & 207 & 325 & 327 & -0.2 \\ 2940 & 0.095 & 0.106 & 122 & 181 & 170 & 1.1 \\ 1960 & 0.000 & 0.000 & 0.00000 & 0.00000 & 0.00009 & -0.9\end{array}$

TiN.

$\Delta R_{0}=0.05, V=20164, Q=0.27,10^{4} a=-\mathrm{I} . \mathrm{I}, 10^{6} b=1.839,10^{11} c=-\mathrm{I} .44$.

$\begin{array}{rrrrrrr}12000 & 0.867 & 0.926 & 0.01060 & 0.01660 & 0.01684 & -2.4 \\ 11000 & 0.819 & 0.874 & 100 I & 154 I & 1527 & I .4 \\ 10000 & 0.737 & 0.789 & 903 & 1383 & 1368 & 1.5 \\ 9000 & 0.648 & 0.694 & 795 & 1215 & 1206 & 0.9 \\ 8000 & 0.556 & 0.597 & 684 & 1044 & 1042 & 0.2 \\ 7000 & 0.460 & 0.494 & 566 & 866 & 872 & -0.6 \\ 6000 & 0.362 & 0.394 & 45 I & 691 & 69 I & 0.0 \\ 5000 & 0.274 & 0.296 & 339 & 519 & 527 & -0.8 \\ 4000 & 0.18 I & 0.196 & 224 & 344 & 35 I & -0.7 \\ 3000 & 0.088 & 0.097 & 11 I & 171 & 17 I & 0.0 \\ 2000 & 0.000 & 0.000 & 0.00000 & 0.00000 & -0.000 I I & I . I\end{array}$


TABLE II (continued).

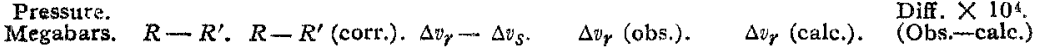

TiN.

$\Delta R_{0}=\mathrm{r} .03, V=20164, Q=0.27,10^{4} a=0.3,10^{6} b=\mathrm{I} .852,10^{11} \mathrm{c}=-0.60$.

$\begin{array}{rrrrrrr}7840 & 0.465 & 0.622 & 0.00712 & 0.01066 & 0.01072 & -0.6 \\ 6860 & 0.386 & 0.525 & 601 & 895 & 896 & -0.1 \\ 5880 & 0.320 & 0.434 & 497 & 732 & 720 & 1.2 \\ 4900 & 0.225 & 0.320 & 366 & 542 & 543 & -0.1 \\ 3920 & 0.143 & 0.209 & 239 & 357 & 364 & -0.7 \\ 2940 & 0.074 & 0.112 & 128 & 187 & 184 & 0.3 \\ 1960 & 0.000 & 0.000 & 0.00000 & 0.00000 & 0.00003 & -0.3\end{array}$

SrLVER.

$\begin{array}{rrrrrrr}\Delta R_{0}=-1.00, V=20191, Q=0.51, I O^{4} a=1 . I, I O^{\prime \prime} b=0.947, c=0 . \\ 12000 & 0.391 & 0.313 & 0.00358 & 0.00958 & 0.00958 & 0.0 \\ 11000 & 0.351 & 0.277 & 317 & 857 & 863 & -0.6 \\ 10000 & 0.312 & 0.243 & 278 & 758 & 768 & -1.0 \\ 9000 & 0.291 & 0.227 & 260 & 680 & 674 & 0.6 \\ 8000 & 0.255 & 0.197 & 225 & 585 & 579 & 0.6 \\ 7000 & 0.211 & 0.159 & 182 & 482 & 484 & -0.2 \\ 6000 & 0.180 & 0.134 & 153 & 393 & 390 & 0.3 \\ 5000 & 0.155 & 0.118 & 135 & 315 & 295 & 2.0 \\ 4000 & 0.102 & 0.076 & 87 & 207 & 200 & 0.7 \\ 3000 & 0.041 & 0.029 & 33 & 93 & 106 & -1.3 \\ 2000 & 0.000 & 0.000 & 0.00000 & 0.00000 & 0.00011 & -1.1\end{array}$

SILVER.

$\Delta R_{0}=0.70, V=20191, Q=0.5 \mathrm{I}, 10^{4} a=0.0,10^{6} b=1.010, c=0$.

$\begin{array}{rrrrrrr}7840 & 0.068 & 0.207 & 0.00237 & 0.00591 & 0.00594 & -0.3 \\ 6860 & 0.055 & 0.178 & 204 & 498 & 495 & 0.3 \\ 5880 & 0.032 & 0.139 & 159 & 394 & 396 & -0.2 \\ 4900 & 0.019 & 0.107 & 122 & 298 & 297 & 0.1 \\ 3920 & 0.009 & 0.075 & 86 & 204 & 198 & 0.6 \\ 2940 & -0.007 & 0.030 & 34 & 93 & 99 & -0.6 \\ 1960 & 0.000 & 0.000 & 0.00000 & 0.00000 & 0.00000 & 0.0\end{array}$

COPPER.

$\begin{array}{rrrrrrr}\Delta R_{0}=0.80, V=20136, Q=0.32, I 0^{4} a=1.0, I 0^{6} b=0.744, c=0 . \\ 12000 & -0.049 & 0.130 & 0.00149 & 0.00749 & 0.00754 & -0.5 \\ 11000 & -46 & 0.123 & 141 & 681 & 680 & 0.1 \\ 10000 & -55 & 0.104 & 119 & 599 & 605 & -0.6 \\ 9000 & -42 & 0.103 & 118 & 538 & 530 & 0.8 \\ 8000 & -43 & 0.089 & 102 & 462 & 456 & 0.6 \\ 7000 & -45 & 0.070 & 80 & 380 & 382 & -0.2 \\ 6000 & -36 & 0.063 & 72 & 312 & 308 & 0.4 \\ 5000 & -19 & 0.060 & 69 & 249 & 233 & 1.6 \\ 4000 & -29 & 0.028 & 32 & 152 & 159 & -0.7 \\ 3000 & -06 & 0.026 & 30 & 90 & 84 & 0.6 \\ 2000 & -0.000 & 0.000 & 0.00000 & 0.00000 & 0.00010 & -1.0\end{array}$


TABLE II (continued). Megabars. $R-R^{\prime} . R-R^{\prime}$ (corr), $\Delta v_{r}-\Delta v_{s} . \quad \Delta v_{r}$ (obs.). $\quad \Delta v_{r}$ (calc.). (Obs-calc.)

COPPER.

\begin{tabular}{|c|c|c|c|c|c|c|}
\hline 7840 & -0.035 & 0.085 & 0.00097 & $0.0045^{1}$ & 0.00456 & -0.5 \\
\hline 6860 & $-0.03 I$ & 0.075 & 86 & 380 & 382 & -0.2 \\
\hline 5880 & -0.029 & 0.063 & 72 & 307 & 308 & $-0 . I$ \\
\hline 900 & -0.019 & 0.055 & 63 & 239 & 233 & 0.6 \\
\hline 20 & -0.020 & 0.035 & 40 & 158 & 159 & $\rightarrow 0.1$ \\
\hline 48 & -0.006 & 0.026 & 30 & 89 & 84 & 0.5 \\
\hline 96 & 0.000 & 0.000 & 0.00000 & 0.00000 & 0.00010 & -1.0 \\
\hline
\end{tabular}

GOLD.

$\Delta R_{0}=-0.35, V=20043, Q=-0.05, \mathrm{IO}^{4} a=0.5, \mathrm{IO}^{6} b=0.566, c=0$.

$\begin{array}{rrrrrrr}12000 & 0.032 & -0.03 I & -0.00036 & 0.00564 & 0.00571 & -0.7 \\ 11000 & 36 & -24 & -28 & 512 & 514 & -0.3 \\ x 0000 & 44 & -12 & -14 & 466 & 4.63 & 0.3 \\ 9000 & 37 & -14 & -16 & 404 & 401 & 0.3 \\ 8000 & 39 & -7 & -8 & 352 & 345 & 0.7 \\ 7000 & 29 & -12 & -14 & 286 & 288 & -0.2 \\ 6000 & 27 & -8 & -9 & 231 & 231 & 0.0 \\ 5000 & 28 & 0.000 & 0 & 180 & 175 & 0.5 \\ 4000 & 19 & -2 & -2 & 118 & 118 & 0.0 \\ 3000 & 13 & 2 & 2 & 62 & 62 & 0.0 \\ 2000 & 0.000 & 0.000 & 0.00000 & 0.00000 & 0.00005 & -0.5\end{array}$

GOLD.

$\begin{array}{lrrrrrr}\Delta R_{\mathrm{o}}=0.01, V=20043, Q=-0.05, \mathrm{IO}^{4} a=0.6, \mathrm{IO}^{6} b=0.57 \mathrm{I}, c=0 . \\ 7840 & -0.01 \mathrm{I} & -0.015 & -0.00017 & 0.00337 & 0.00342 & -0.5 \\ 6860 & -0.006 & -0.010 & -\mathrm{II} & 283 & 286 & -0.3 \\ 5880 & 0.003 & 0.000 & 0 & 235 & 230 & 0.5 \\ 4900 & 0.011 & 0.009 & 10 & 186 & 174 & 1.2 \\ 3920 & 0.005 & 0.003 & 3 & 1.21 & 118 & 0.3 \\ 2940 & 0.003 & 0.002 & 2 & 61 & 62 & -0.1 \\ 1960 & 0.000 & 0.000 & 0.00000 & 0.00000 & 0.00006 & -0.6\end{array}$

BISMUTH.

$\Delta R_{0}=-0.28, V=20008, Q=-0.68,10^{4} a=0.9,10^{6} b=2.923,10^{11} c=-2.38$.

\begin{tabular}{|c|c|c|c|c|c|c|}
\hline 12000 & 1.936 & 1.819 & 0.02099 & 0.02699 & 0.02694 & 0.5 \\
\hline 11000 & 1.768 & I. 653 & 1908 & 2448 & 2447 & $0 . I$ \\
\hline 10000 & I . 593 & I . 483 & I7II & $219 \pi$ & 2195 & -0.4 \\
\hline 9000 & $\mathrm{I} .423$ & 1.319 & 1522 & 1942 & 1938 & 0.4 \\
\hline 8000 & I. $23 \mathrm{I}$ & I. 134 & 1309 & 1669 & 1677 & -0.8 \\
\hline 7000 & I. 036 & 0.950 & 1096 & 1396 & $I_{4} I I$ & -1.5 \\
\hline 6000 & 0.856 & $0.78 \mathrm{I}$ & 901 & $\mathrm{II}_{4} \mathrm{I}$ & Ir 40 & O.I \\
\hline 5000 & 0.666 & 0.605 & 698 & 878 & 864 & $\mathrm{I} .4$ \\
\hline 4000 & 0.469 & $0.42 \mathrm{I}$ & 487 & 607 & 584 & 2.3 \\
\hline 3000 & 0.225 & 0.200 & $23 I$ & $29 \mathrm{I}$ & 299 & -0.8 \\
\hline 2000 & 0.000 & 0.000 & 0.00000 & 0.00000 & 0.00009 & -0.9 \\
\hline
\end{tabular}


TABLE II (continued).

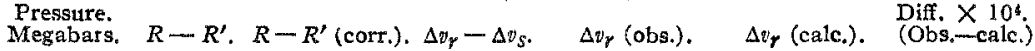

BISMUTH.

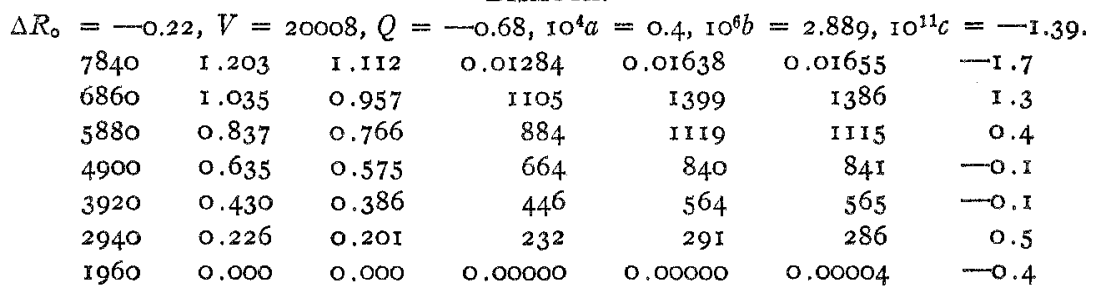

Tin-BISMUTh ALLOY.

\begin{tabular}{|c|c|c|c|c|c|c|}
\hline $\begin{array}{l}R_{0}=- \\
\quad \mathrm{2} 2000\end{array}$ & $\begin{array}{l}\text { I, } V= \\
\text { I. } 567\end{array}$ & $\begin{array}{c}\text { or } 35, Q \\
\text { I. } 446\end{array}$ & $\begin{array}{l}0.03, \mathrm{IO}^{4} a \\
0.01658\end{array}$ & $\begin{aligned}= & 1.3,10^{6} b \\
& 0.02258\end{aligned}$ & $\begin{array}{l}2.295,10 \\
0.02259\end{array}$ & $=-0.2$ \\
\hline I 1000 & I . 420 & x.305 & 1497 & 2037 & 2038 & -0.1 \\
\hline 10000 & I . 282 & I.I7I & I34I & $I 82 \mathrm{I}$ & 1818 & 0.3 \\
\hline 9000 & I . 123 & 1.019 & I I 68 & I 588 & I 595 & -0.7 \\
\hline 8000 & 0.982 & 0.887 & 1017 & 1377 & 1372 & 0.5 \\
\hline 7000 & 0.831 & 0.747 & 856 & I 156 & 1149 & 0.7 \\
\hline 6000 & 0.674 & $0.60 \mathrm{I}$ & 689 & 929 & 923 & 0.6 \\
\hline 5000 & 0.516 & 0.456 & 523 & 703 & 698 & 0.5 \\
\hline 4000 & 0.347 & 0.304 & 348 & 468 & 470 & -0.2 \\
\hline 3000 & 0.179 & 0.157 & 180 & 240 & 242 & -0.2 \\
\hline 2000 & 0.000 & 0.000 & 0.00000 & 0.00000 & 0.00013 & -1.3 \\
\hline
\end{tabular}

TOOL, STEEI.

$\Delta R_{0}=-0.79, V=20060, Q=0.03,10^{4} a=0.2,10^{6} b=0.602, c=0$

$\begin{array}{rrrrrrr}7840 & 0.097 & 0.003 & 0.00003 & 0.00357 & 0.00356 & 0.1 \\ 6860 & 0.083 & 0.000 & 0 & 294 & 297 & -0.3 \\ 5880 & 0.071 & 0.000 & 0 & 235 & 238 & -0.3 \\ 4900 & 0.061 & 0.004 & 4 & 180 & 179 & 0.1 \\ 3920 & 0.050 & 0.009 & 10 & 128 & 120 & 0.8 \\ 2940 & 0.020 & -0.003 & -3 & 56 & 61 & -0.5 \\ 1960 & 0.000 & 0.000 & 0.00000 & 0.00000 & 0.00002 & -0.2\end{array}$

Sir,ica Grass.

$\begin{array}{rrrrrrr}\Delta R_{0}= & -0.40, V= & 20107, Q=-0.22,10^{4} C=-\mathrm{I} .0,10^{6} b=3.157, c=0 . \\ 7840 & \mathrm{I} .376 & \mathrm{I} .318 & 0.015 \mathrm{II} & 0.01865 & 0.01848 & \mathrm{I} .7 \\ 6860 & \mathrm{I} .132 & \mathrm{I} .080 & 1238 & 1532 & 1538 & -0.6 \\ 5880 & 0.907 & 0.860 & 986 & 122 \mathrm{I} & 1228 & -0.7 \\ 4900 & 0.677 & 0.638 & 731 & 907 & 919 & -1.2 \\ 3920 & 0.458 & 0.428 & 49 \mathrm{I} & 609 & 609 & 0.0 \\ 2940 & 0.227 & 0.211 & 242 & 301 & 300 & 0.1 \\ 1960 & 0.000 & 0.000 & 0.00000 & 0.00000 & -0.00010 & 1.0\end{array}$

In determining the value of $V_{\gamma}-V_{s}$ at 2000 megabars, our fixed initial pressure, it is necessary to use an approximate value of the compressibility up to 2000 . The first step in the calculation was to interpolate the observed values of $R-R^{\prime}$ to correspond with the even Iooo's of megabars. '

I In some of the earlier measurements pressures were read close to the even rooo's of $\mathrm{kg} . / \mathrm{cm}^{2}$, and for those cases in Table II their equivalents in megabars are given. 
Since the pressures seldom differed from the level rooo's by more than Io megabars, this interpolation was very easy and simplified the succeeding calculations to a considerable extent.

The results of our measurements are presented in Table II. In the successive columns reading from left to right are (I) the pressure in megabars; (2) the corresponding values of $R-R^{\prime}$ in millimeters; (3) $R-R^{\prime}$, corrected according to the right-hand side of Equation $6 ;(4)$ the difference in volume change per $\mathrm{cc}$. between the given sample and soft steel, and (5) $\Delta v_{r}$ the change in volume per cc. at atmospheric pressure of the material between the pressures $P$ and $P_{0}$ (2000 megabars). Above each séries of measurements are given the corresponding values of $\Delta R_{\circ}, V$ (the volume in cu. $\mathrm{mm}$. of the test piece at atmospheric pressure), and $Q\left(=V_{r}-V_{s} / A\right)$ which was calculated from the difference in volumes of $r$ and $s$ at $P=$ 2000 .

In the method of calculation as given above, it is assumed that the temperature is constant throughout any one run and also that the series of measurements with the standard test piece are made at the same temperature as the series with the other test piece. The corrections necessitated by variations in temperature are shown in Table III, which has been calculated from Bridgman's data on the compressibility of kerosene at various temperatures, ${ }^{1}$ assuming a $45 \mathrm{~mm}$. column of kerosene. In this table the column headed $\mathrm{A}$ gives the change in $R-R^{\prime}$ which would restult if the $R$ - series of readings were made while the bomb is one degree warmer than when the $R^{\prime}-$ readings were taken. Under $\mathrm{B}$ are given the values of the change due to any one reading of either $R$ or $R^{\prime}$ being made at a temperature one degree higher than that of the remainder of the series.

Table III.-Corrections in Piston Displacementi Mm. Per Deg.

$\begin{array}{ccc}\text { Pressure, megabars. } & \text { A. } & \text { B. } \\ 2000 & 0.000 & -0.025 \\ 3000 & 0.003 & -0.023 \\ 4000 & 0.005 & -0.020 \\ 5000 & 0.007 & -0.019 \\ 6000 & 0.007 & -0.018 \\ 7000 & 0.007 & -0.018 \\ 8000 & 0.007 & -0.018 \\ 9000 & 0.007 & -0.018 \\ 10000 & 0.008 & -0.017 \\ 11000 & 0.010 & -0.016 \\ 12000 & 0.011 & -0.014\end{array}$

During the course of a series of measurements the temperature of the bomb was read at frequent intervals by means of a copper-constantan thermo-element which was inserted at $B$ (Fig. $x$ ). Owing to the large

${ }^{1}$ P. W. Bridgmar, Proc. Am. Acad., 48, 357 (1912). 
heat capacity of the heavy bomb-weighing about $40 \mathrm{~kg}$.-the fluctuations in temperature during the course of any one run were seldom greater than $0 . I^{\circ}$. Moreover, the respective temperatures of two corresponding $R$ and $R^{\prime}$ series usually differed by not more than $1.0^{\circ}$. We were therefore able to dispense with a thermostat, small corrections according to Table III being made when necessary.

\section{Discussion of Results.}

Change of Compressibility with Pressure.-The graphs obtained by plotting $P$ as abscissa and $\Delta v$ as ordinate and passing the best smooth curve through the points are grouped in Figs. 9, IO, II, and I2, which for the sake of clearness have been drawn to different scales. It can readily be

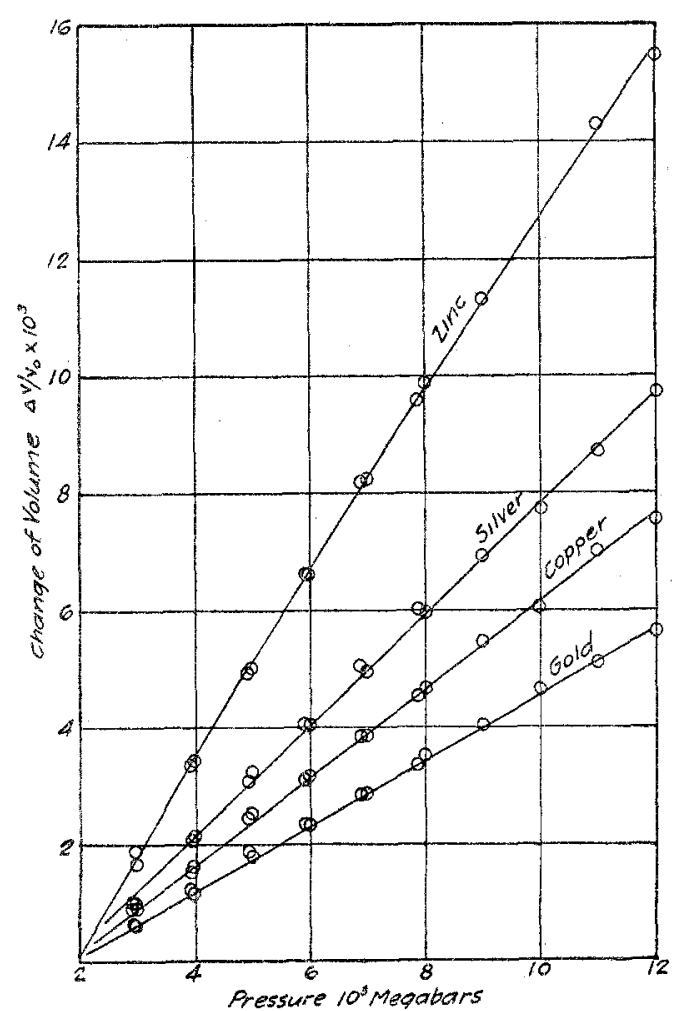

Fig. 9.-Final results for $\Delta V$, volume change under pressure of $\mathrm{Au}, \mathrm{Cu}, \mathrm{Ag}$ and $\mathrm{Zn}$. seen that these graphs are nearly straight lines, but a closer inspection, more especially when the plots are constructed on a larger scale, reveals the fact that some of the lines are more or less curved. The results for tool steel, gold, copper, brass, silver, aluminum and calcium carbonate are represented satisfactorily by straight lines, but for each of the remaining materials the points seem to lie in a slightly curved line concave toward the $P$ axis.

Since the slope of any one of these lines at any point is equal to the compressibility at the corresponding pressure, and since the results indicate a slight but unmistakable curvature for the more compressible substances, from the change of slope it is possible to obtain a rough estimate of the change of compressibility with pressure. In order to accomplish this, the coefficients of the equation

$$
\Delta v=a+b\left(P-P_{0}\right)+c\left(P-P_{0}\right)^{2}
$$

were calculated for each run separately using the method of least squares. The value of $c$ is very small in any case and for those series of measure- 
ments which by inspection were seen to be represented satisfactorily by straight lines, $c$ in Equation 8 was put equal to zero, and the best straight line calculated from the data. In Table II the values of $a, b$, and $c$ for each series are given, while the last two columns of the table contain, respectively; $\Delta v$ calculated from Equation 8 , and $\Delta v_{\text {obs. }}-\Delta v_{\text {calc. }}$.

The earlier runs recorded in Table II were carried up to only 8000 $\mathrm{kg} . / \mathrm{cm}^{2}$. (7840 megabars). Subsequently new measurements were made on most of the materials at pressures from 2000 to 12000 megabars. The concordance of the two runs, which were made with the same samples of the materials, is in most cases quite satisfactory. It should be noted that a value of $\mathrm{r} . \mathrm{O}$ in the last column of Table II corresponds to an error in $R$ of less than $0.01 \mathrm{~mm}$.; similarly a difference of 0.01 between two values of $10^{6} b$ signifies an error in $R$ of the same amount. The values of $a$ have no significance except (I) as an indication of the error in $R$ at 2000 megabars, and (2) as a constant in the equation from which the values of $\Delta v_{r}$ (calc.) were obtained. A difference of $\mathrm{I} . \mathrm{O}$ in the value of $10^{4} a$ corresponds to a difference of less than 0.01 $\mathrm{mm}$. in $R$, the reading of the micrometer. The average deviation of the individual observations may thus be seen to be less than $0.006 \mathrm{~mm}$.,

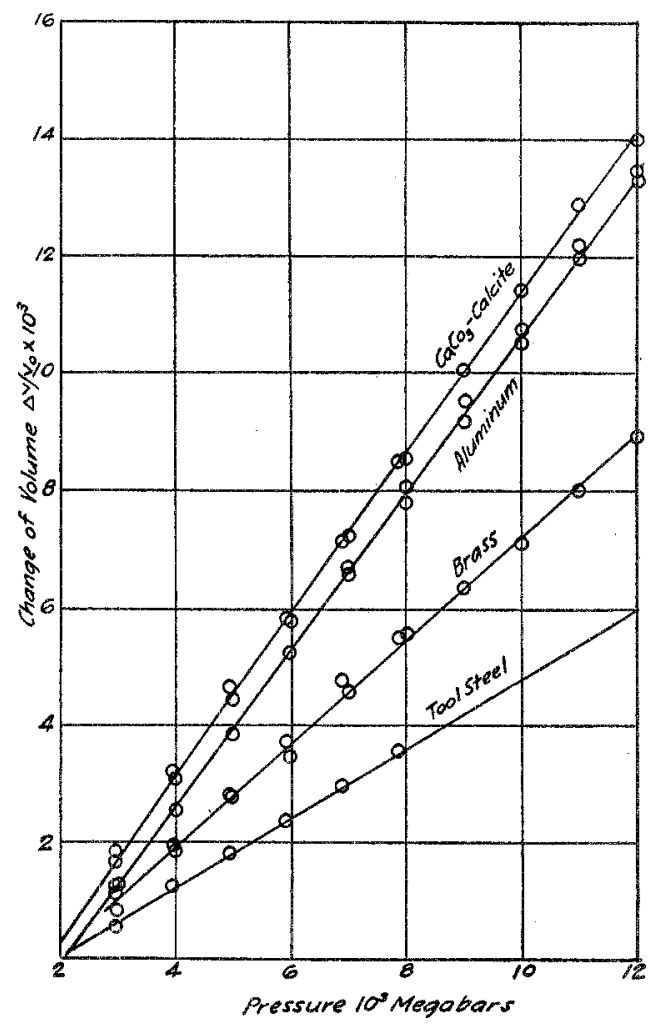

Fig. 10.-Final results for $\Delta V$, volume change under pressure of tool steel, brass, Al and calcite. while two runs on the same substance seldom differ by more than two or three hundredths of a millimeter. The value of $c$ is a measure of the change of compressibility with pressure; it is a very small quantity and except for the more compressible substances not much weight is to be attached to it.

In Table IV, which summarizes the results of our measurements on compressibility, the weighted averages of the coefficients $b$ and $c$ are given. The averages were obtained by weighting for $b$, the longer runs twice as 
much as the shorter ones; for $c$ the ratio was four to one. From these average values of $b$ and $c$ the compressibilities, at zero pressure and at 10,000 megabars, were calculated and are shown in Cols. 4 and 5 , respectively. The last column indicates how much the compressibility $k$ decreases between $o$ and Io,000 megabars. The values recorded in this column are to be considered merely as rough estimates and not at all as precise determinations of this very small quantity. Indeed, these num-

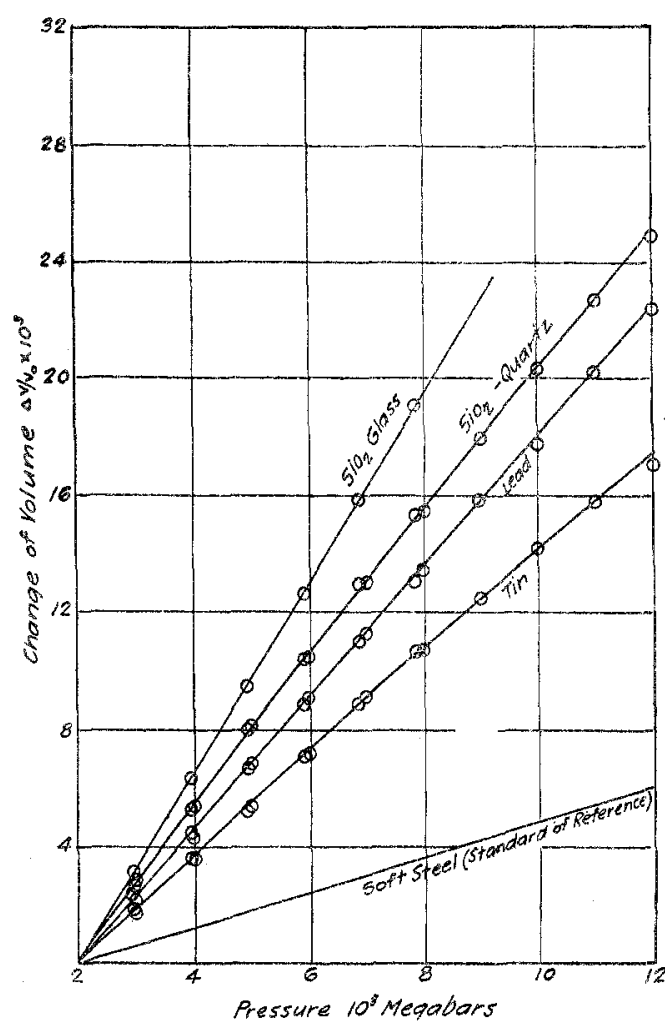

Fig. Ix.-Final results for $\Delta V$, volume change under pressure of $\mathrm{Sn}, \mathrm{Pb}$, quartz and $\mathrm{SiO}_{2}$-glass. The assumed $P$-V graph of iron (soft steel) is also included. bers as given are not necessarily within $25 \%$ of their true value, but at least they are indicative of the order of magnitude of the change in compressibility with pressure. It is to be noted that the above discussion presupposes that the relation between $P$ and $\Delta v$ for the reference substance, soft steel, is linear; consequently that the curvature as given is a minimum, because the graph for soft steel if it should prove to be not linear would of necessity also be concave toward the $P$-axis.

An examination of the figures shows that while in general the substances having the greatest compressibility exhibit the greatest decrease in compressibility with pressure, yet no strict relation between $k$ and $\Delta k$ is observable. For zinc and cadmium the values of $\Delta k$ are abnormally high, while on the other hand the

$P-\Delta v$ data for lead, calcite, and aluminum are represented surprisingly well by a straight line.

In this connection it is of interest to note that even if $k$ were defined as being equal to $d v / v d P$ instead of $d v / v_{0} d P k$ would still show a decrease with increasing pressure. In other words, $k$ decreases faster than $V$. For instance, the volume of soditum chloride is decreased $4 \%$ by a pressure of ro,ooo megabars but at the same time, as shown by 
Table IV, $k$ decreases $14 \%$; therefore $I d V / V d P$ decreases approximately 10\%.

TAale IV.-Summary of Results ARranged in Order of Decreastng ComPRESSIBILITY.

\begin{tabular}{|c|c|c|c|c|c|c|}
\hline \multirow[b]{2}{*}{ Material. } & \multicolumn{2}{|c|}{ Coeff. of Eq. 8.} & \multicolumn{2}{|c|}{$\begin{array}{l}\text { Compressibility, } k, \\
\text { per megabar, } \times 10^{6} \text {. }\end{array}$} & \multirow{2}{*}{$\begin{array}{c}k \times 10^{\sharp} \\
\text { att } 300 \\
\text { (Richards.) }\end{array}$} & \multirow{2}{*}{$\begin{array}{c}\Delta k / k_{0}, \text { change } \\
\text { of } k \text { between } \\
0 \text { and lo000 } \\
\text { megabars. } \% .\end{array}$} \\
\hline & $b \times 10^{5}$ & $c \times 10^{11}$ & At 0 . & At 10,000 . & & \\
\hline$\ldots \ldots \ldots$ & 4.006 & 2.95 & 4.12 & $3 \cdot 53$ & $\cdots$ & 14 \\
\hline $\mathrm{SiO}_{2}$, glass.......... & 3.156 & . & 3.1 & . & . & . \\
\hline$B i \ldots \ldots \ldots \ldots \ldots$ & $2.91 \mathrm{I}$ & 2.18 & 3.00 & 2.57 & 3.0 & I 5 \\
\hline $\mathrm{SiO}_{2}$, quartz........ & 2.625 & I.94 & 2.70 & 2.31 & . & $\mathrm{I}_{4}$ \\
\hline Sn-Bi............. & 2.295 & 0.49 & $2.3 \mathrm{I}$ & 2.22 & . & 4 \\
\hline $\mathrm{Cd}, \ldots \ldots \ldots \ldots \ldots$ & 2.134 & 2.52 & 2.24 & 1.70 & $2 . I$ & 22 \\
\hline $\mathrm{Pb} \ldots \ldots \ldots \ldots \ldots$ & 2.202 & 0.24 & $2.2 \mathrm{I}$ & 2.16 & 2.33 & 2 \\
\hline Snn............... & I. 843 & $\mathrm{r} .27$ & 1.89 & I. 64 & I.9 & I3 \\
\hline $\mathrm{Zn} \ldots \ldots \ldots \ldots \ldots$ & I. 677 & I. 52 & I. 74 & I. 43 & I. 7 & $\mathrm{I}_{7}$ \\
\hline $\mathrm{CaCO}_{3}$, calcite. ...... & I.390 & . & & .39 & $\cdots$ & . \\
\hline$A 1 \ldots \ldots \ldots \ldots \ldots$ & 1.324 & . & & .32 & $\mathrm{I} .48$ & . \\
\hline $\mathrm{Ag} \ldots \ldots \ldots \ldots \ldots$ & 0.968 & . & & .97 & I .OI & . \\
\hline Brass............. & 0.887 & . & & .89 & .. & .. \\
\hline $\mathrm{Cu} \ldots \ldots \ldots \ldots \ldots$ & 0.749 & . & & .75 & 0.76 & . \\
\hline Tool steel. . . . . . . . . & 0.602 & $\cdots$ & & .60 & .. & . \\
\hline Au. . & 0.568 & .. & & .57 & 0.64 & . \\
\hline Fe (soft steel) ....... & $\ldots$ & . & & .60 & . & $\cdots$ \\
\hline
\end{tabular}

Comparison with Previous Results.-About the only other determinations of compressibilities with which to compare our results are those carried out at pressures between 100 and 500 megabars by Richards ${ }^{1}$ and his collaborators. An inspection of Cols. 4 and 6 of Table IV shows on the whole a fair agreement between our results (extrapolated to zero pressure) and those of Richards. Our value for aluminum is $1.32 \times 10^{-6}$, while Richards obtained $\mathrm{x} .48 \times \mathrm{10}^{-6}$. Bridgman has also determined the compressibility of aluminum ${ }^{2}$ and reports it as $1.19 \times 10^{-6}$ (I.I 7 referred to the $\left.\mathrm{kg} . / \mathrm{cm}^{2}\right)$. It is difficult to account for the rather wide discrepancy here, unless it is due to different amounts of impurities in the samples of metal used. Aluminum usually contains significant amounts of silica and also iron. As may be seen from the analysis (see above) our aluminum contained $0.235 \% \mathrm{Si}$ and $0.016 \% \mathrm{Fe}$. Neither Bridgman nor Richards report any analysis of the aluminum which they used.

The compressibilities of several kinds of crystals have been calculated by Voigt from his measurements of their elastic constants. His results ${ }^{3}$ for sodium chloride, quartz, and calcite, when recalculated to the megabar standard, are as follows: sodium chloride, 4.13; quartz, 2.65; and calcite,

'T. W. Richards, el al., Carnegie Inst. Publications 76; ThIs Journal, 37, 470, I643 (I9I5).

${ }^{2}$ P. W. Bridgman, Proc. Am. Acad., 44, 279 (1909).

${ }^{3}$ W. Voigt, Ann. Phys, 3I, 720 (1887); 35, 655 (1888); 39, 430 (1890). 
I.54. With the exception of calcite these values show a surprising agreement with our own determinations.

Compressibility of Mixtures.-Two different types of alloys were studied: copper-zinc (ordinary brass), and tin-bismuth. Mixtures of copper and zinc show a complicated liquidus curve which indicates a large amount of solid solution, while tin and bismuth form a simple binary system with one eutectic, no compounds, and practically no solid solution. In order to compare the compressibilities of the alloys with those

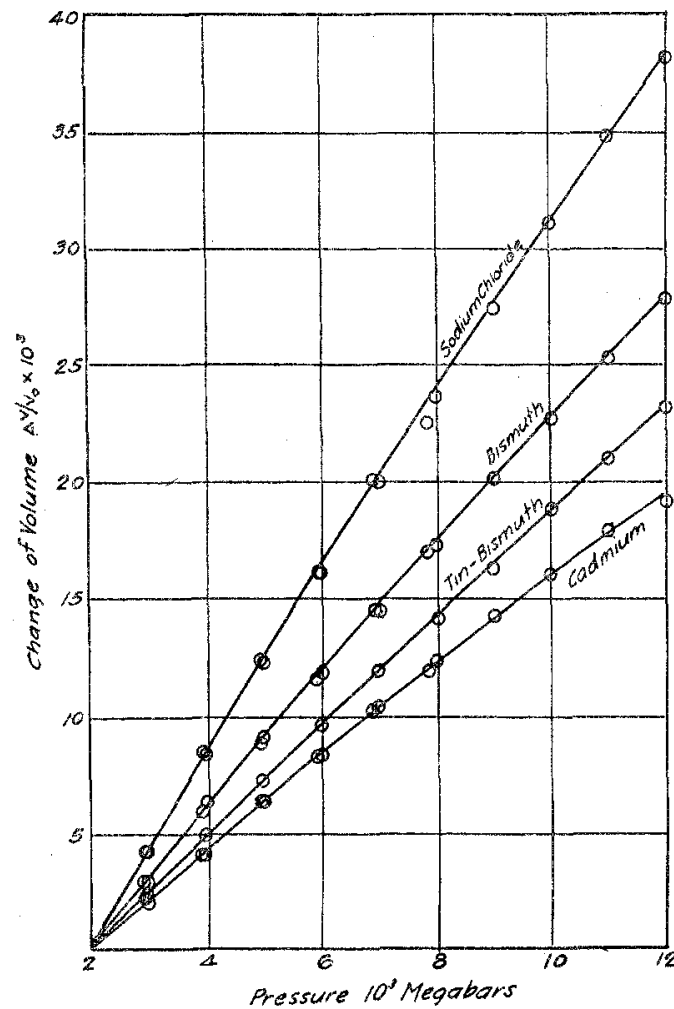

Wig. r2.-Final results for $\Delta V$, volume change under pressure of $\mathrm{Cd}, \mathrm{Sn}-\mathrm{Bi}$ alloy, $\mathrm{Bi}$ and $\mathrm{NaCl}$.

bars, respectively).

The agreement is much better for the tin-bismuth alloy than for brass. Thus is the case of the former average "calculated" value is $5 \%$ higher than the average observed value, but the corresponding discrepancy for brass is $25 \%$. Now an alloy such as brass belongs to that type of mixture, the physical properties of which ordinarily do not bear a simple relation to the properties of the end members of the series, while on the other hand, many of the physical properties of the simple mixtures, such percentages by volume of each component was multiplied by its compressibility. The sum of these products was then the "calculated" compressibility. Thus brass contained by weight $\mathrm{Cu}$ $61.8 \%, \mathrm{Zn} 35.9 \%$, and $\mathrm{Pb}$ $2.3 \%$ (in addition to $0.05 \%$ Fe which may be neglected). The corresponding composition by volume was, therefore, $\mathrm{Cu} 56.9 \%, \mathrm{Zn} 4 \mathrm{I} .4 \%$, and $\mathrm{Pb}$ I. $6 \%$, and the "calculated" compressibility was I.I8 at zero pressure and I.05 at I0,000 megabars. The observed compressibility was 0.89 at both pressures. For the tin-bismuth alloy, containing $\mathrm{Sn} 53.3 \%$ and $\mathrm{Bi}$ $46.7 \%$ by volume, the "calculated" compressibilities were 2.40 and 2.07 , while the observed values were $2.3 \mathrm{I}$ and 2.22 (at $o$ and 10,000 megaof the pure components, the 
as the tin-bismuth alloy, vary linearly with the amount of the components. Therefore, in view of the results noted above, it is perhaps not unteasonable to assume that for purposes of calculation, compressibility may be considered as a colligative property when applied to mixtures whose other properties, such as specific volume, electrical conductivity, specific heat, and so forth, are approximately linear functions of the composition.

Possible Hysteresis Effects.-Since the measurements which have been recorded were made under conditions of decreasing pressure, it is of interest to find out to what extent the curvature of some of the $P-\Delta v$ graphs (Figs. Io to I3) may be due to a hysteresis of the volume change under hydrostatic pressure. It is, of course, not easily conceivable that a single crystal, or part of a single crystal, would exhibit any lack of uniformity in the volume strain caused by uniform hydrostatic pressure, or would show any hysteresis in its volume elasticity; but many of the materials examined consisted of a crystalline aggregate for which the relation between stress and strain might not be the same as for a single crystal of the same substance. In order to detect a possible hysteresis in the volume change, measurements were made on a number of the materials with increasing pressure. In carrying out these determinations, pairs of readings of pressure and piston displacement were taken at 2000, 4000 , and 6000 megabars for each of the materials, including soft steel, and the difference in compressibility between steel and the material in question calculated in the usual way. The volume changes $(\Delta v)$ determined in this way were found to be, in certain cases, slightly lower than the corresponding values of $\Delta v$ obtained with increasing pressure. The differences, however, proved to be hardly greater than the uncertainty in the measurements and are probably not worth while recording here. The hysteresis in connection with the change with pressure in the volume of materials such as we have used is therefore probably negligible.

\section{Summary.}

A description is given of a method for measuring the compressibilities of solids under hydrostatic pressure, and results are presented for I6 materials at pressures up to 12,000 megabars. The essence of this method. is to compare the change of volume under pressure of a cylinder of the material with that of a similar cylinder of soft steel the compressibility of which was considered to be $0.60 \cdot 10^{-6} \mathrm{~cm}^{2}$./megadyne at all pressures. In carrying out the determination the solid, surrounded by a liquid such as kerosene, was inclosed in a thick-walled steel bomb fitted with a movable leak-proof piston, and pairs of simultaneous readings were taken of (I) the displacement of the piston, i. e., the volume change, and (2) the pressure. The piston displacement was measured to better than o.or $\mathrm{mm}$. by means of a dial micrometer. In measuring the pressure advantage was 
taken of the change of resistance under pressure of a "therlo" wire, and in order to determine the pressure to within one megabar the resistance change was measured with a type of Wheatstone bridge having no movable contacts.

The $P$ - $\Delta v$ graph for gold, copper, brass, silver, aluminum, and calcite, like that of steel, is sensibly linear; but the graph for zinc, tin, cadmium, lead, tin-bismuth alloy, quartz, bismuth, and sodium chloride shows an appreciable curvature, ${ }^{1}$ thus indicating for those substances a measurable decrease of compressibility with increasing pressure.

A comparison was made of the compressibility of two alloys with that of their components. In the case of a simple mixture such as the tinbismuth alloy, the measurements indicate that the compressibility of mixtures whose other properties, such as specific volume, electrical conductivity, and specific heat, are approximately linear functions of the composition, is related in the same simple way to the compressibilities of the separate components. On the other hand, the compressibility of alloys of the class to which brass belongs is much lower than the sum of the individual compressibilities.

WASAINCTON, D. C.

[CONTRIBUTION FROM Kent Chamical Laboratory, University of Chicago.]

\section{A STUDY OF THE EMANATION METHOD OF DETERMINING THORIUM.}

BY G. H. CARTIEDGE.

Received September 9, 1918.

The well-known emanation method is the best one for estimating small amounts of radium. But thorium cannot be determined similarly because of the very short period of its amanation. However, it has been proposed to modify the method by circulating air continuously through the solution of the thorium preparation and through the ionization chamber noting the activity when the system has reached a steady state.

Although there are a few references in the literature to such a method, ${ }^{2}$ so far as the author is aware no one except Joly ${ }^{3}$ has ever used it for quantitative purposes; and in that work it was applied only to the analysis of ordinary rocks containing thorium to the extent of about $1 \mathrm{O}^{-5} \mathrm{~g}$. per gram of rock.

In view of the great practical value of a simple method of estimating thorium without the necessity of separating it from the other rare earths generally occurring with it in nature, and of the importance of such a

1 The measurements on silica glass were not extended far enough to determine satisfactorily the amount of its change of compressibility.

2 Soddy, "Chemistry of Radioelements."

${ }^{3}$ Joly, Phil. Mag., 17, 760 (1909). 